\title{
The formation of impossible rings in macrocyclooligomerizations for cyclodepsipeptide synthesis: the 18-from-12 paradox
}

\author{
Abigail N. Smith and Jeffrey N. Johnston* \\ Department of Chemistry and Vanderbilt Institute of Chemical Biology, \\ Vanderbilt University, Nashville, Tennessee 37235 \\ *Email: jeffrey.n.johnston@vanderbilt.edu
}

\section{Contents}

Supplementary Experimental Results..... 3

Figure S1. MCO reaction schemes for didepsipeptide (5) and tetradepsipeptide (1) ............................................. 3

General MCO Purification Information 3

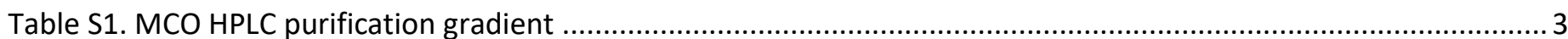

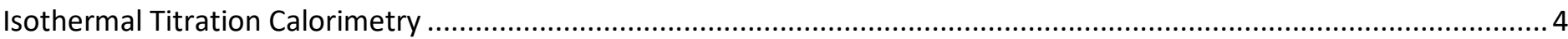

Table S2: Summary of experimentally determined thermodynamic values for binding ........................................... 4

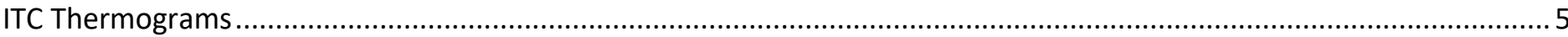

Figure S2. ITC isotherms for the titration of (A) $\mathrm{NaPF}_{6}(5.00 \mathrm{mM})$ and (B) $\mathrm{KSCN}(5.00 \mathrm{mM})$ into $16(300 \mu \mathrm{M})$ in $\mathrm{MeOH}$ at $25{ }^{\circ} \mathrm{C}$.

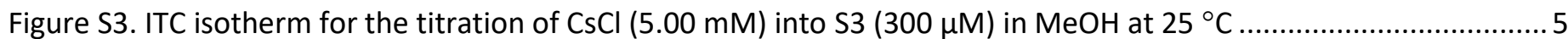

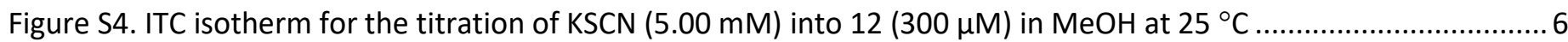

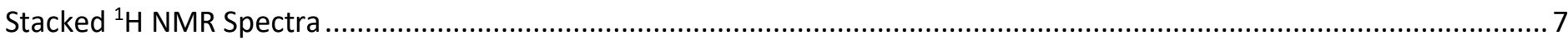

Figure S5. Full-scale ${ }^{1} \mathrm{H}$ NMR spectrum of authentic samples of all COD ring sizes ...............................................

Figure S6. Expansion of ${ }^{1} \mathrm{H}$ NMR spectrum of authentic samples of all COD ring sizes from 5.8-3.8 ppm..................... 7

Figure S7. ${ }^{1} \mathrm{H}$ NMR of 18-Membered Ring (16) with varying amounts of residual trifluoroacetic acid from reverse phase HPLC purification

Figure S8. ${ }^{19} \mathrm{~F}$ NMR of 18-membered ring (16) with varying amounts of residual trifluoroacetic acid from reverse phase

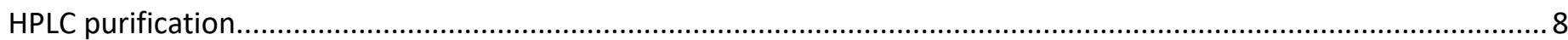

Figure S9. ${ }^{1} \mathrm{H}$ NMR of three different samples of 18-Membered Ring (16) with no residual TFA present.......................9

Figure S10. ${ }^{1} \mathrm{H}$ NMR expansion from 5.5-4.1 ppm of three different samples of 18-Membered Ring (16) with no residual TFA present

30-Membered versus "60-Membered" Ring Data....

Figure S11. (A) Full scale HRMS of 30-membered ring (S3), (B) MS/MS of 1018 peak in a sample of 30-membered ring from MCO with the tetradepsipeptide, (C) MS/MS of 1018 peak in a sample of 30-membered ring from MCO with the didepsipeptide

Figure S12. ${ }^{1} \mathrm{H}$ NMR of 30-membered ring (S3) samples from MCO reaction with didepsipeptide and MCO reaction with tetradepsipeptide with no residual TFA present

Figure S13. ${ }^{1} \mathrm{H}$ NMR of 30-membered ring (S3) samples from MCO reaction with didepsipeptide and MCO reaction with tetradepsipeptide with no residual TFA present

Figure S14. ${ }^{1} \mathrm{H} \mathrm{NMR}\left(600 \mathrm{MHz}, \mathrm{CDCl}_{3}\right)$ of 11 


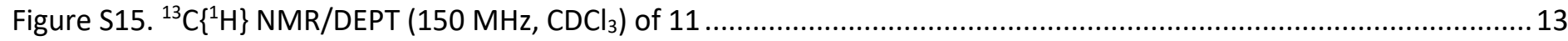

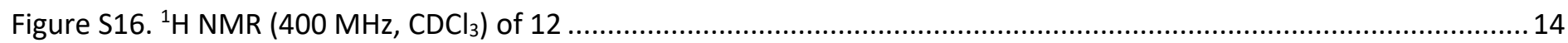

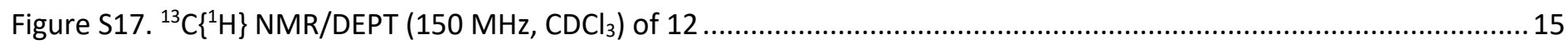

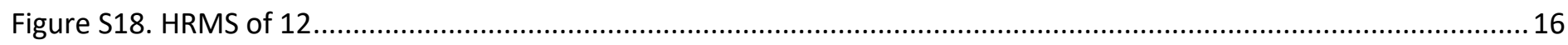

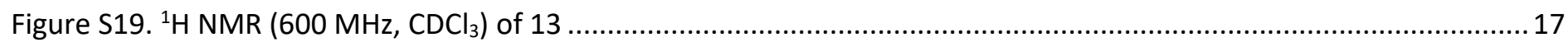

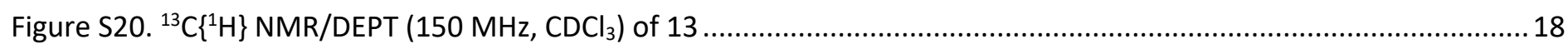

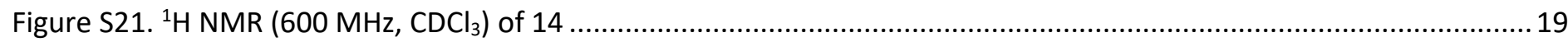

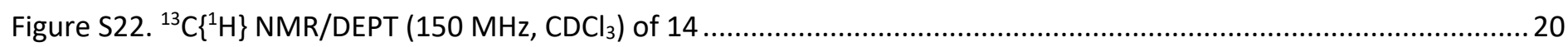

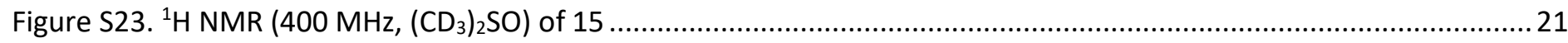

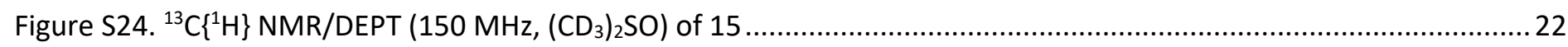

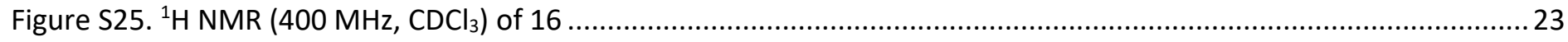

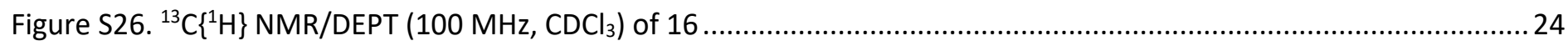

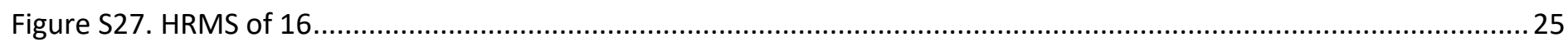

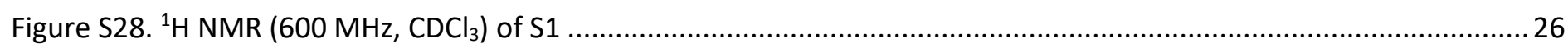

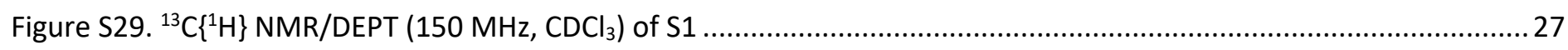

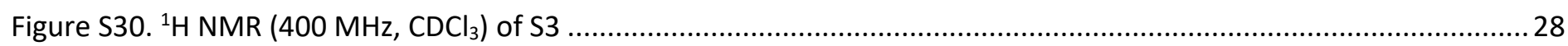

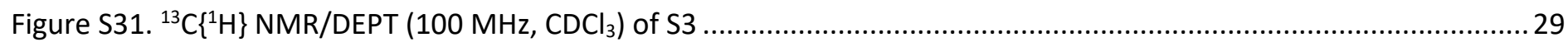

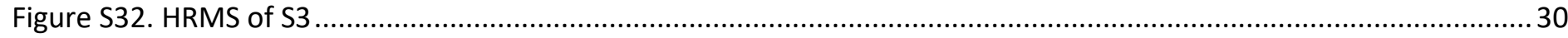




\section{Supplementary Experimental Results}

Details on MCO reaction profile from monomer 5 and 1:
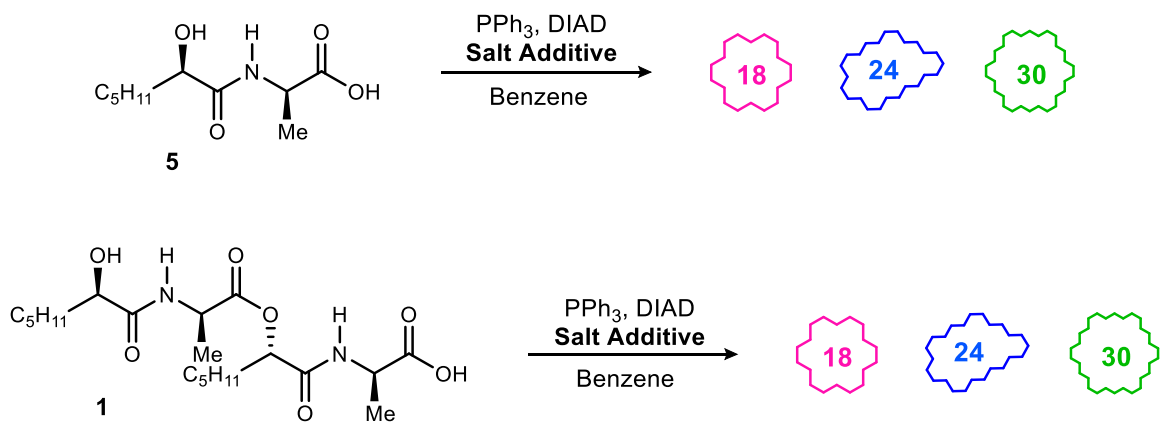

Figure S1. MCO reaction schemes for didepsipeptide (5) and tetradepsipeptide (1)

- The macrocycles reported in the main text are the only sizes that were isolated from the respective MCO reactions.

- The total isolated yield of the macrocycles from the didepsipeptide (5) MCO reaction without salt additives was $57 \%(18,24$, and 30 membered rings). The material previously assigned as the 36 -membered ring formed in this reaction is now reassigned to the 18 -membered ring, thereby increasing the yield for that ring-size. ${ }^{1}$

- The total isolated yield of the macrocycles from the tetradepsipeptide (1) reaction without salt additives was $70 \%$ (18, 24, and 30 membered rings). There are no 36 or 60 -membered rings formed in this reaction as was previously reported. ${ }^{1}$

- In these cases, with the corrected macrocycle sizes and yields, and when salt additives are used, no templating effect can be justified until the mechanism of paradox ring-formation is determined.

- The characterization data for the 24 membered ring matches what was previously reported. ${ }^{1}$ The 18 and 30 membered ring have revised characterization data, so a full characterization is reported here for both.

- Corrected yields are reported in the main text.

\section{General MCO Purification Information}

Preparative HPLC was performed on an Agilent 1260 system (column: Zorbax Eclipse XDB-C18; $21.2 \mathrm{~mm} \times 150 \mathrm{~mm}, 5$ $\mu \mathrm{m}, 8 \mathrm{~mL} / \mathrm{min}$ flow rate) with 210, 254, and $198 \mathrm{~nm}$ monitoring wavelength. The gradient used is listed in Table S1.

\begin{tabular}{|c|c|}
\hline Time (min) & $\% \mathrm{MeCN}$ \\
\hline 2.0 & 5 \\
\hline 9.0 & 40 \\
\hline 20.0 & 87 \\
\hline 30.0 & 87 \\
\hline 37.0 & 95 \\
\hline 40.0 & 5 \\
\hline 43.0 & 5 \\
\hline
\end{tabular}

Table S1. MCO HPLC purification gradient

\footnotetext{
${ }^{1}$ Batiste, S. M.; Johnston, J. N. Rapid synthesis of cyclic oligomeric depsipeptides with positional, stereochemical, and macrocycle size distribution control, Proc. Natl. Acad. Sci. U. S. A. 2016, 16462.
} 


\section{Isothermal Titration Calorimetry}

General Information: ITC measurements were performed using a Microcal PEAQ-ITC instrument (MicroCal Inc.

Northampton, MA). All experiments were performed at $25{ }^{\circ} \mathrm{C}$ in anhydrous methanol. Optimal settings for consistent results in methanol include reference power set to $5 \mu \mathrm{cal} / \mathrm{mol}$, stir speed set to $1000 \mathrm{rpm}$ and instrument feedback set to low. These settings are important for methanol in order to avoid instrumental overcompensation for measured heats.

Instrument Preparation, Sample Loading, Experimental Titration Details, and Data Analysis: The preparation, experimental detail, and data analysis all follow the procedures we have previously reported. ${ }^{2}$

\begin{tabular}{|c|c|c|c|c|c|c|}
\hline Macrocycle & $\begin{array}{c}\text { Metal } \\
\text { Ion }\end{array}$ & $\mathbf{K}_{\mathrm{a}}\left(\mathbf{M}^{-\mathbf{1}}\right)$ & $\mathbf{N}$ & $\begin{array}{c}\mathbf{\Delta H} \\
\left(\mathbf{k c a l ~ m o l}^{-\mathbf{1}}\right)\end{array}$ & $\begin{array}{c}\Delta \mathbf{G} \\
\left(\mathbf{k c a l ~ m o l}^{-\mathbf{1}}\right)\end{array}$ & $\begin{array}{c}-\mathbf{T} \Delta \mathbf{S} \\
\left(\mathbf{k c a l ~ m o l}^{-\mathbf{1}}\right)\end{array}$ \\
\hline $\mathbf{1 6}$ & $\mathrm{Na}^{+}$ & $(1.49 \pm 0.21) \times 10^{5}$ & 2.08 & $-0.103 \pm 0.002$ & -7.06 & -6.96 \\
\hline $\mathbf{1 6}$ & $\mathrm{K}^{+}$ & $(1.60 \pm 0.22) \times 10^{4}$ & 0.98 & $-0.146 \pm 0.007$ & -5.74 & -5.59 \\
\hline $\mathbf{S 3}$ & $\mathrm{Cs}^{+}$ & $(1.98 \pm 0.54) \times 10^{4}$ & 0.51 & $-0.093 \pm 0.012$ & -5.86 & -5.77 \\
\hline $\mathbf{1 2}$ & $\mathrm{K}^{+}$ & $(2.72 \pm 0.37) \times 10^{4}$ & 0.54 & $-0.130 \pm 0.007$ & -6.06 & -5.93 \\
\hline
\end{tabular}

Table S2: Summary of experimentally determined thermodynamic values for binding

\footnotetext{
${ }^{2}$ Batiste, S. M.; Johnston, J. N. Evidence for Ion-Templation During Macrocyclooligomerization of Depsipeptides, J. Am. Chem. Soc. 2018, 140, 4560.
} 
ITC Thermograms

Isotherms for the 18, 30, and 36 membered rings are shown. Isotherms for the 24 membered ring are unchanged from the original report and not shown here. ${ }^{2}$

(A)
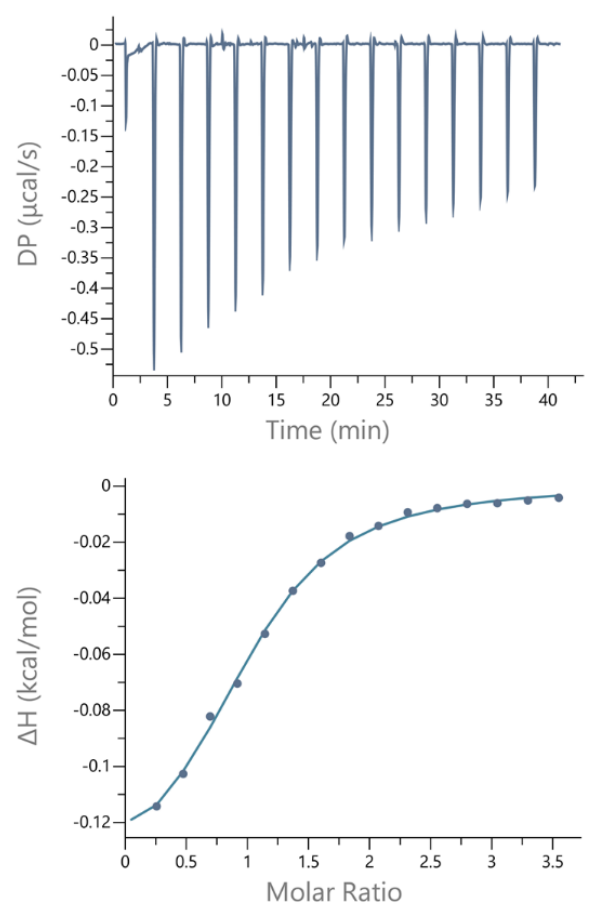

(B)
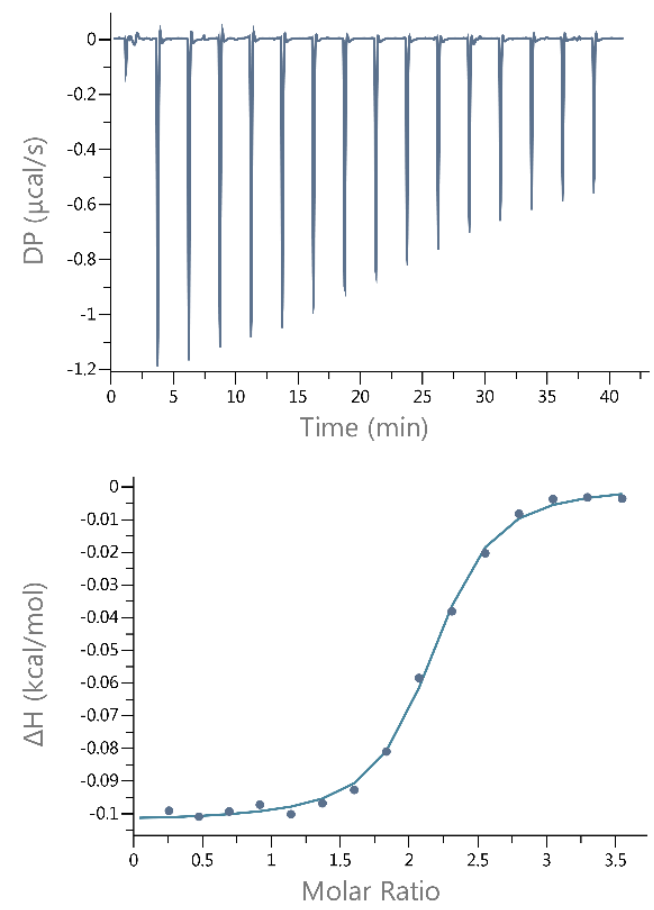

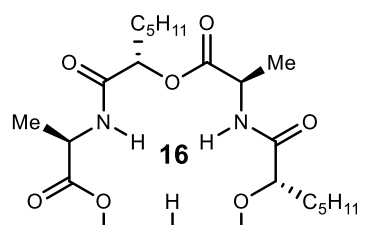

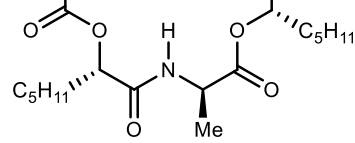

Figure S2. ITC isotherms for the titration of (A) $\mathrm{NaPF}_{6}(5.00 \mathrm{mM})$ and (B) KSCN (5.00 mM) into $16(300 \mu \mathrm{M})$ in $\mathrm{MeOH}$ at $25{ }^{\circ} \mathrm{C}$
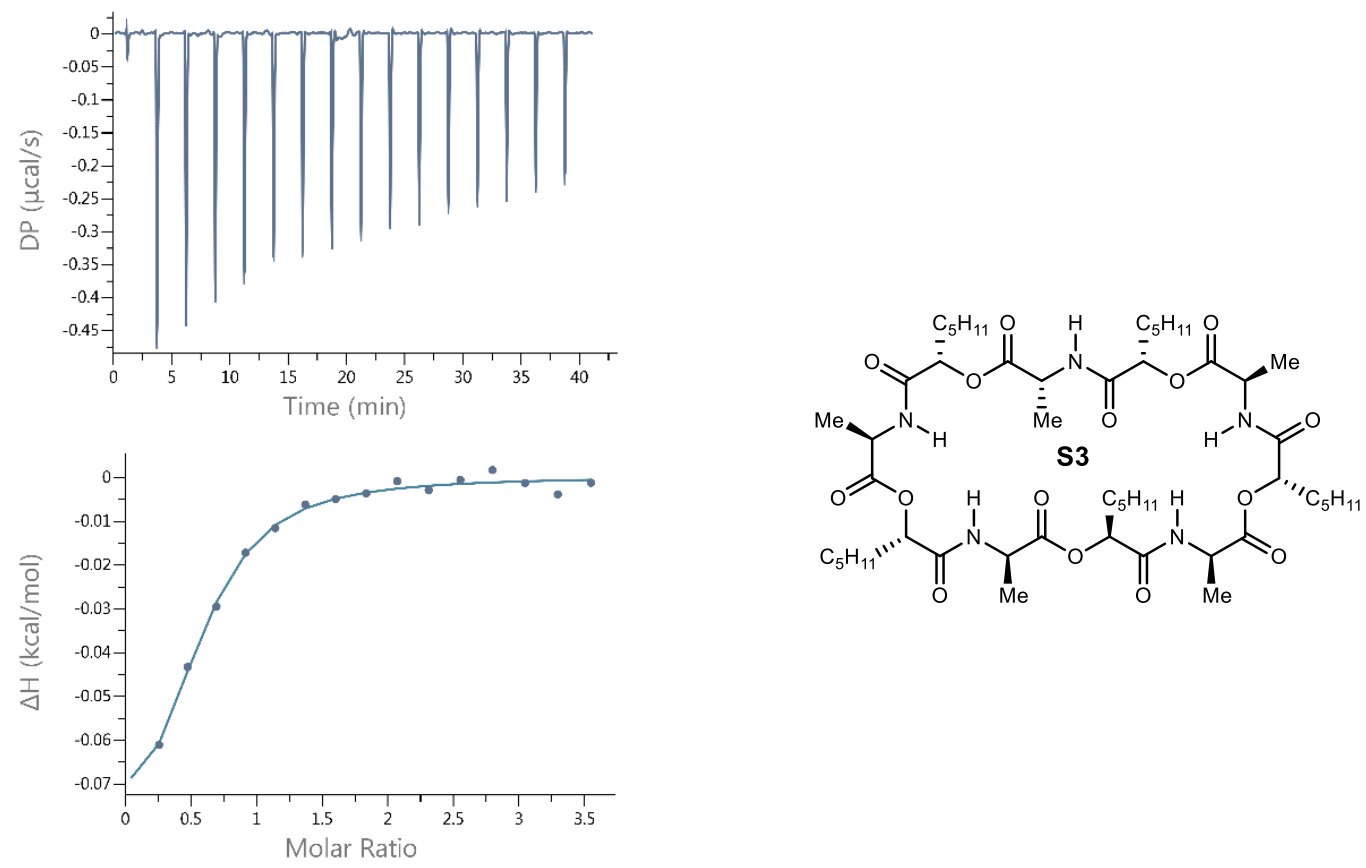

Figure S3. ITC isotherm for the titration of $\mathrm{CsCl}(5.00 \mathrm{mM})$ into $\mathbf{S 3}(300 \mu \mathrm{M})$ in $\mathrm{MeOH}$ at $25^{\circ} \mathrm{C}$ 

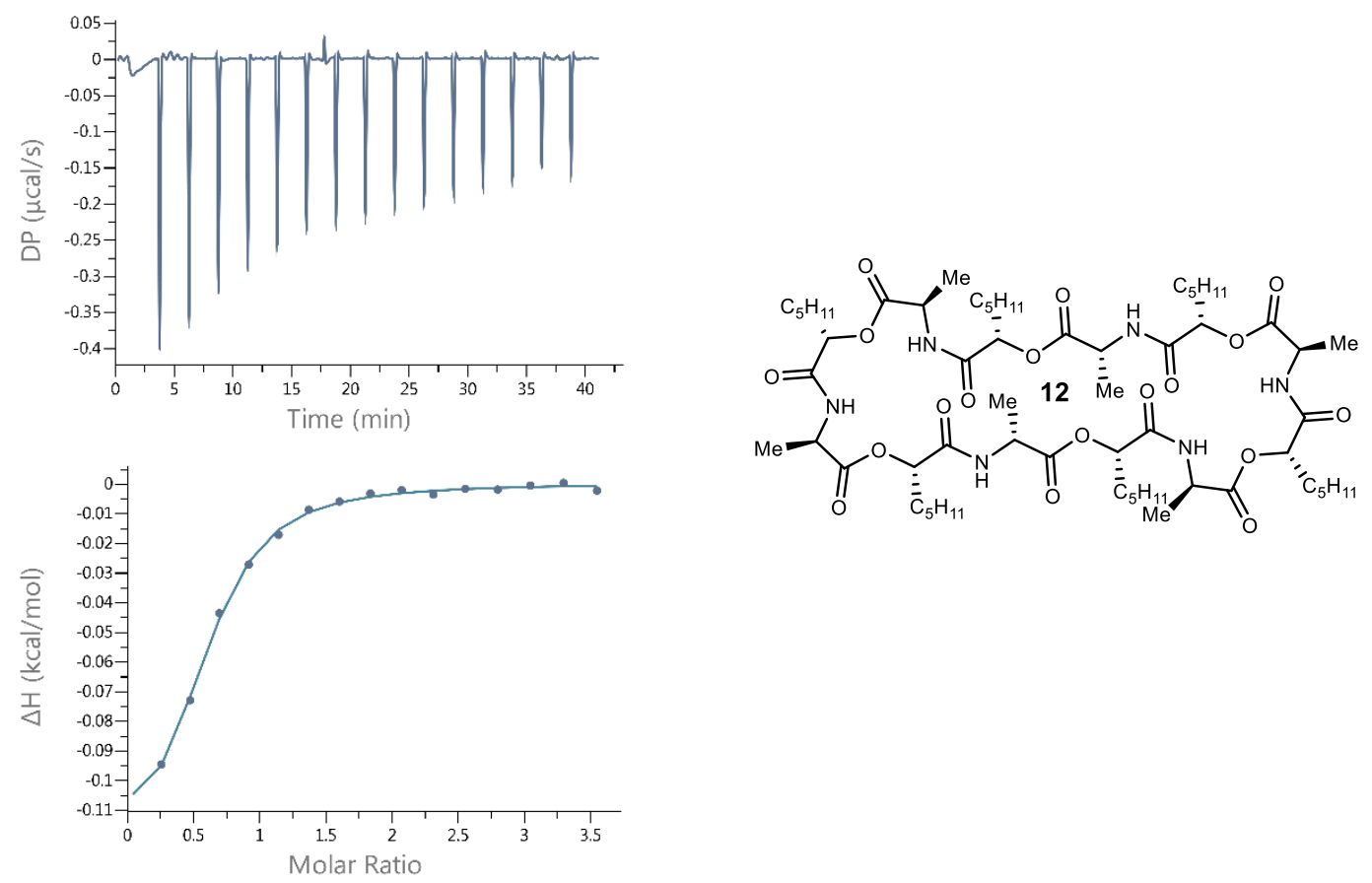

Figure S4. ITC isotherm for the titration of KSCN (5.00 mM) into $12(300 \mu \mathrm{M})$ in $\mathrm{MeOH}$ at $25^{\circ} \mathrm{C}$ 


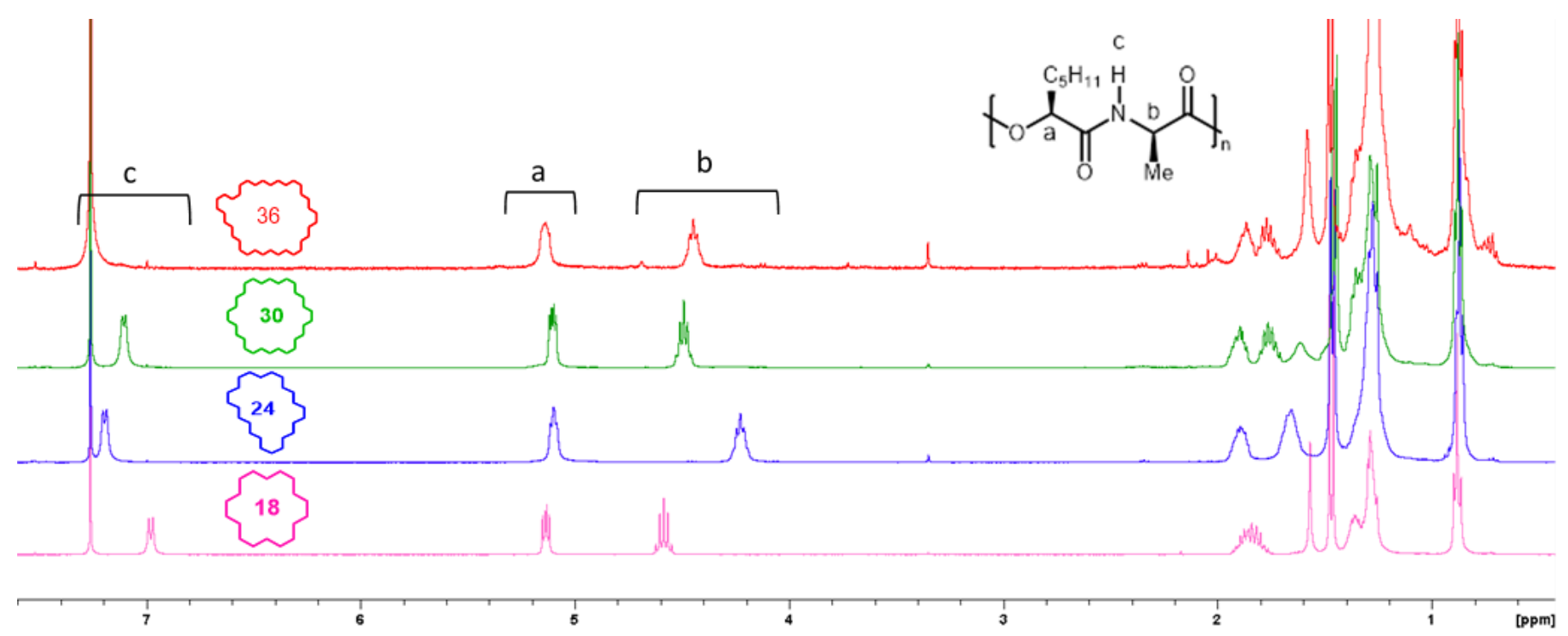

Figure S5. Full-scale ${ }^{1} \mathrm{H}$ NMR spectra of authentic samples of all COD ring sizes

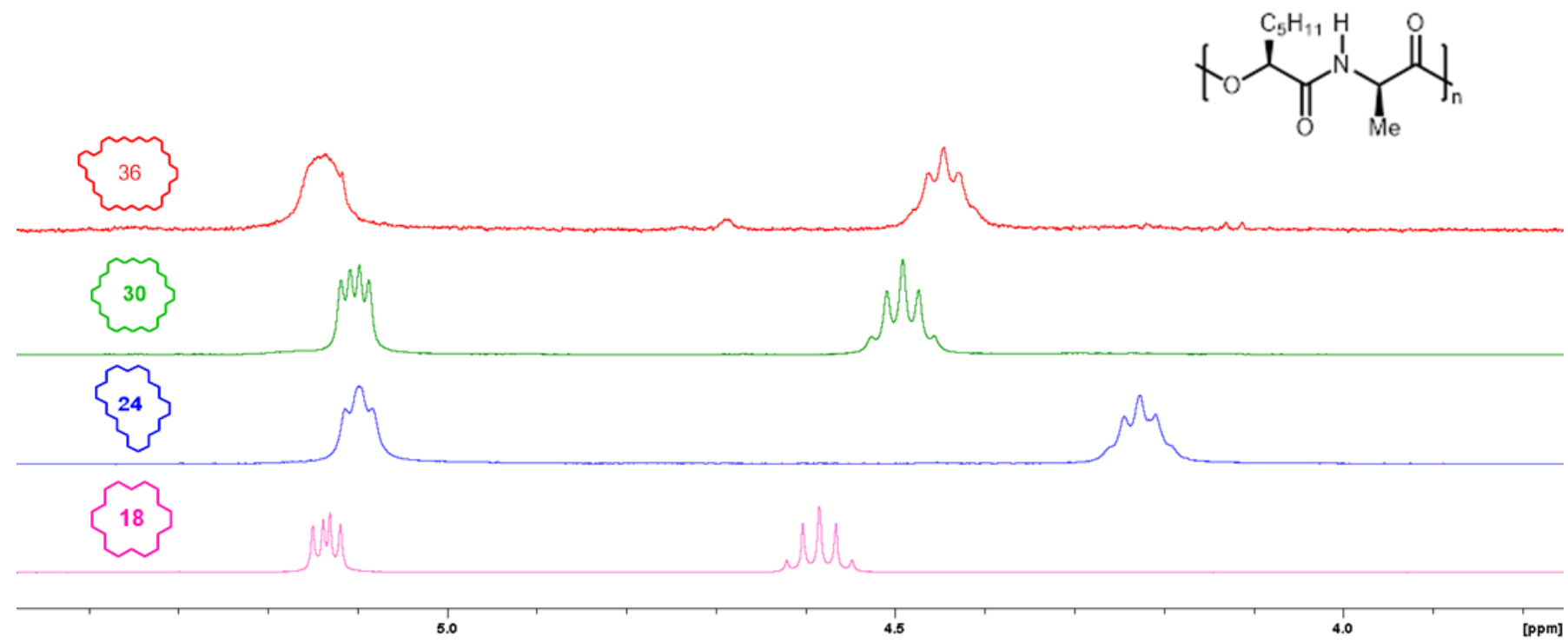

Figure S6. Expansion of ${ }^{1} \mathrm{H}$ NMR spectra of authentic samples of all COD ring sizes from 5.8-3.8 ppm. 


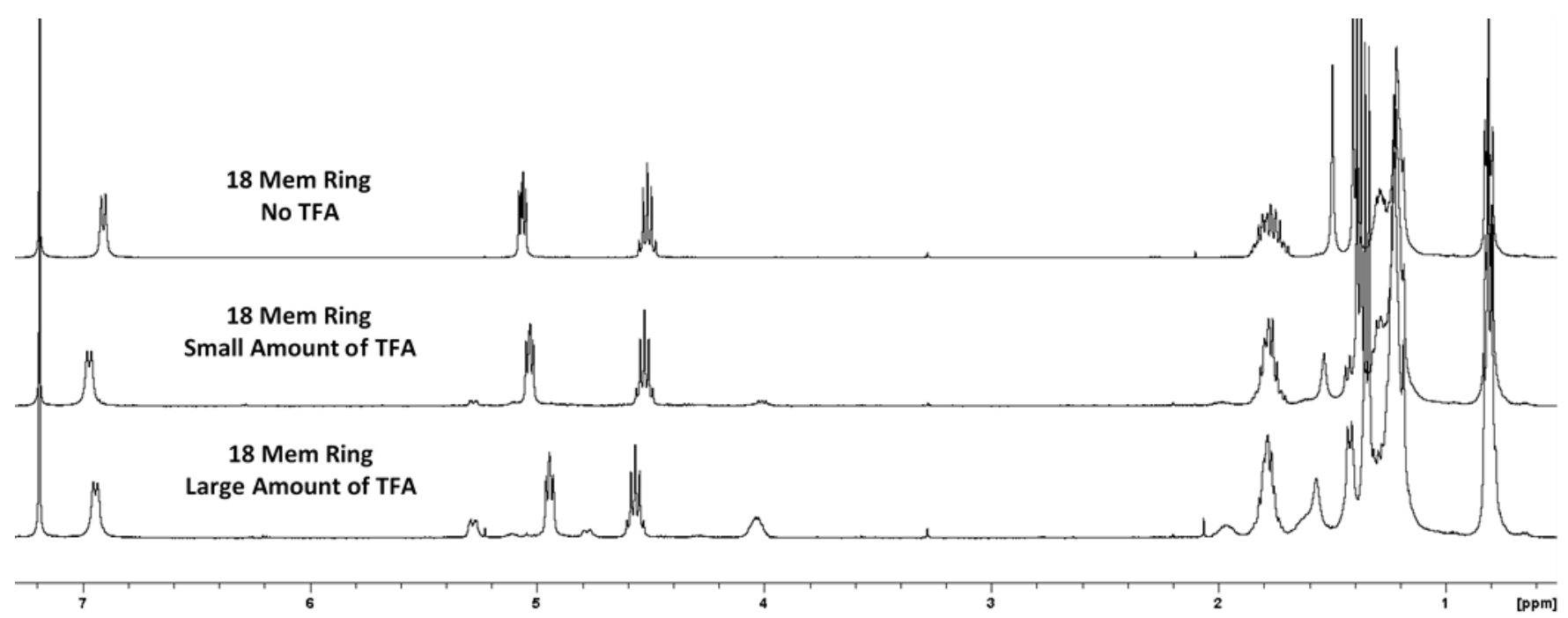

Figure S7. ${ }^{1} \mathrm{H}$ NMR of 18-Membered Ring (16) with varying amounts of residual trifluoroacetic acid from reverse phase HPLC purification

18 Mem Ring

No TFA

18 Mem Ring

Small Amount of TFA

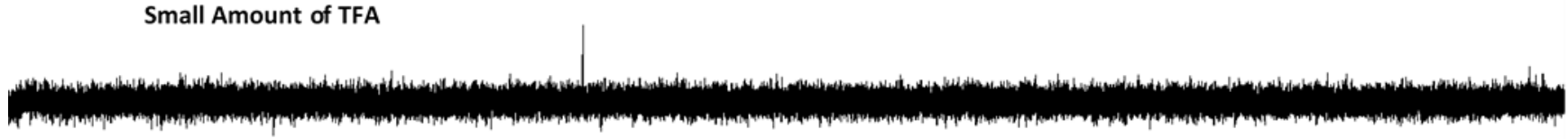

18 Mem Ring

Large Amount of TFA

.50

$-100$

$-150$

[ppm]

Figure S8. ${ }^{19} \mathrm{~F}$ NMR of 18-membered ring (16) with varying amounts of residual trifluoroacetic acid from reverse phase HPLC purification 


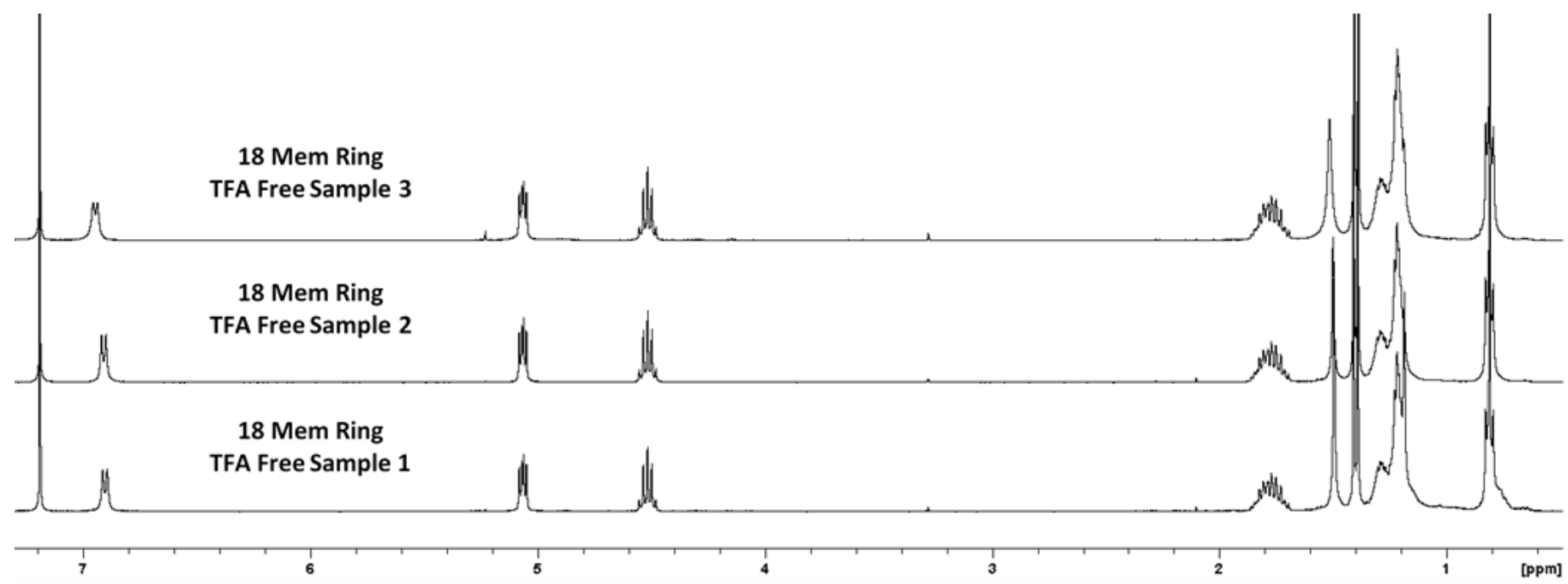

Figure S9. ${ }^{1} \mathrm{H}$ NMR of three different samples of 18 -Membered Ring (16) with no residual TFA present

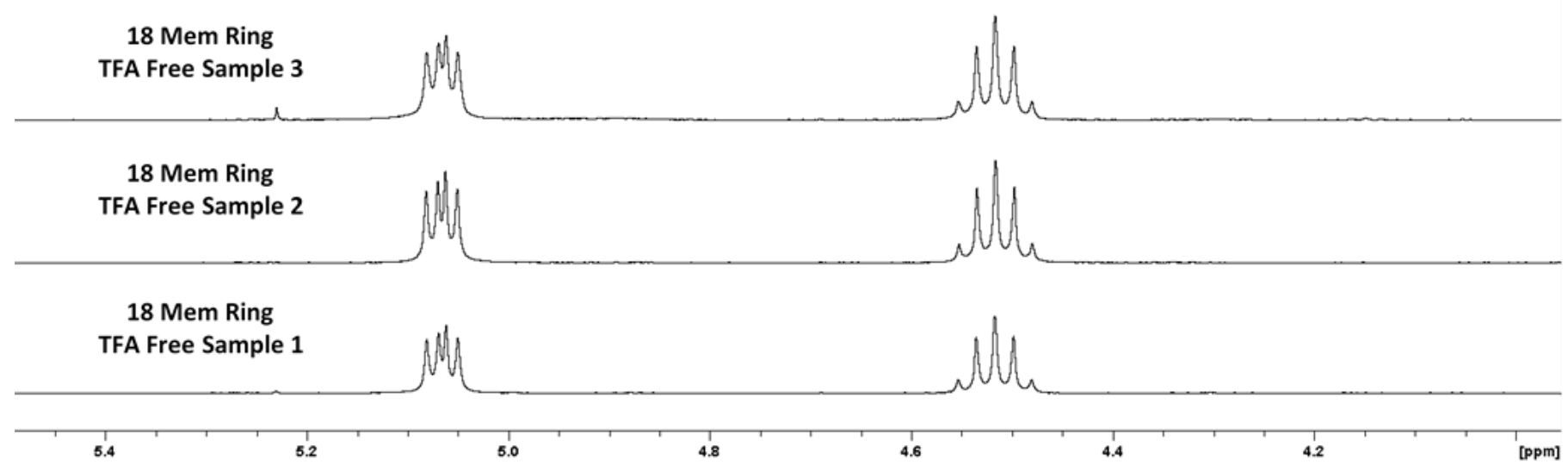

Figure S10. ${ }^{1} \mathrm{H}$ NMR expansion from 5.5-4.1 ppm of three different samples of 18-Membered Ring (16) with no residual TFA present 


\section{0-Membered versus "60-Membered" Ring Data}

The original belief that a 60 -membered ring existed ${ }^{1}$ was based on the same logic that was used for the 36 -membered ring - from the MCO reaction with a tetradepsipeptide, a 30-membered ring should not be possible. Therefore, one that has similar characteristics could be a macrocycle twice its size (60-membered ring). Based on our discovery that the originally characterized "36-membered" ring is actually the 18-membered ring, we believe the originally characterized "60-membered" ring is actually the 30-membered ring. Again, the slight differences in ${ }^{1} \mathrm{H}$ NMR are due to residual TFA, and once removed, the spectra overlap (Figure S12 and Figure S13). Furthermore, when the original sample of what was assigned as the 60-membered ring was resubjected to HRMS analysis, the peak corresponding to a 60-membered ring was not observed. The HRMS data instead looked effectively identical to the 30-membered ring. We hypothesize that the HRMS peak for the 60-membered ring may have been an artifact. Furthermore, MS/MS on the 1018 ion (mass of the 30-membered ring) are identical between both samples from the MCO with the didepsipeptide and tetradepsipeptide. Due to the similarity between the cases, we did not find it necessary to make an authentic sample of a 60-membered COD.

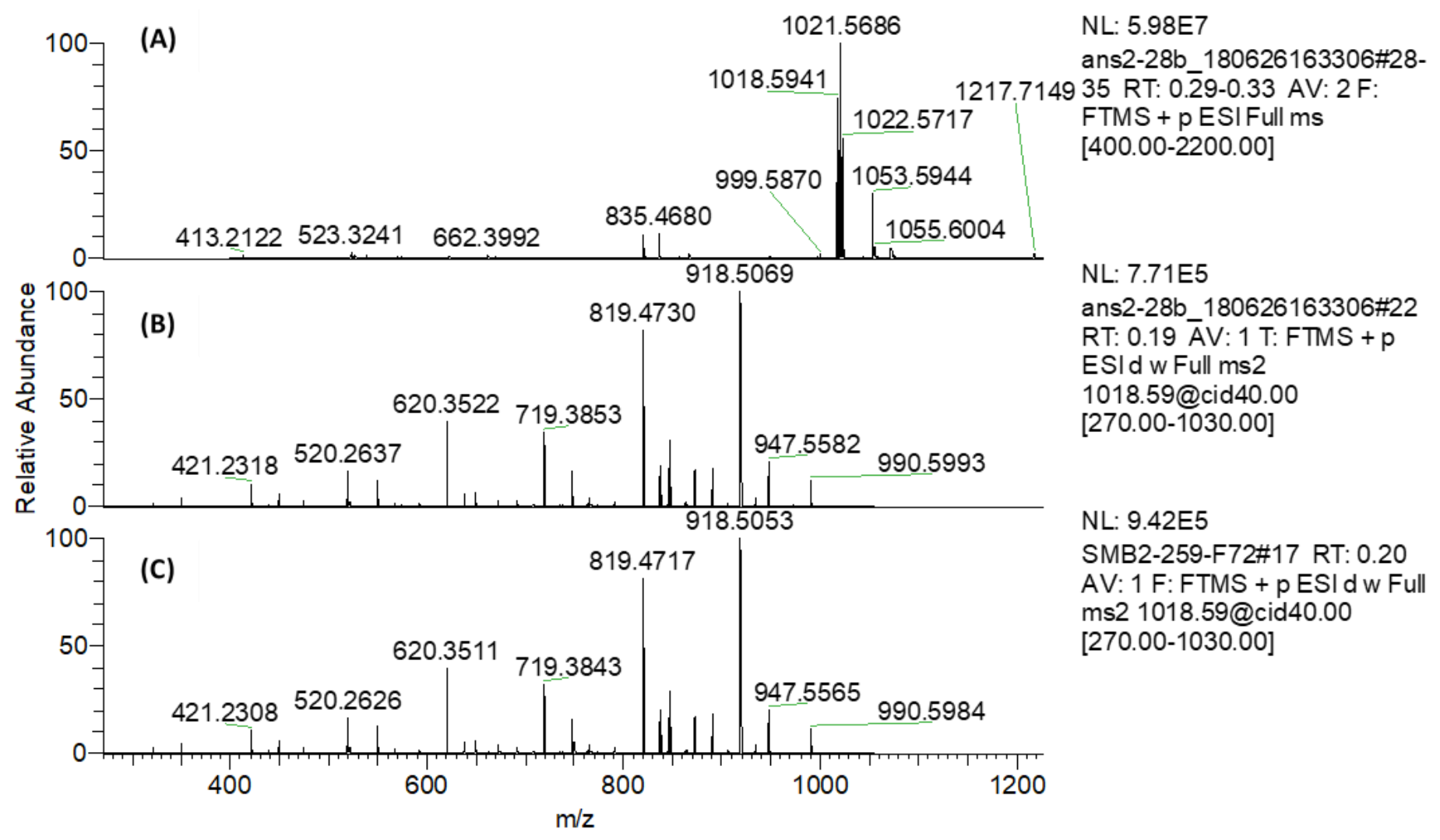

Figure S11. (A) Full scale HRMS spectrum of 30-membered ring (S3), (B) MS/MS of 1018 peak in a sample of 30membered ring from MCO with the tetradepsipeptide, (C) MS/MS of 1018 peak in a sample of 30-membered ring from MCO with the didepsipeptide 


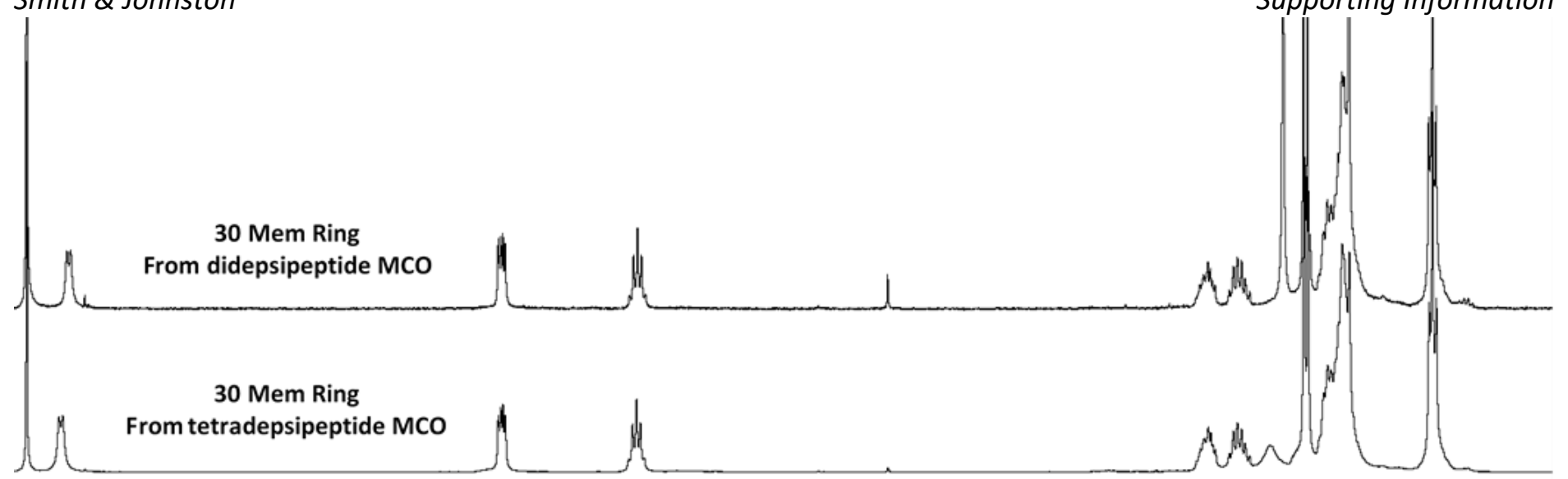

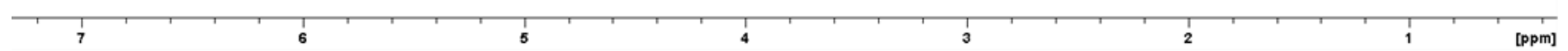

Figure S12. ${ }^{1} \mathrm{H}$ NMR of 30 -membered ring (S3) samples from MCO reaction with didepsipeptide and MCO reaction with tetradepsipeptide with no residual TFA present

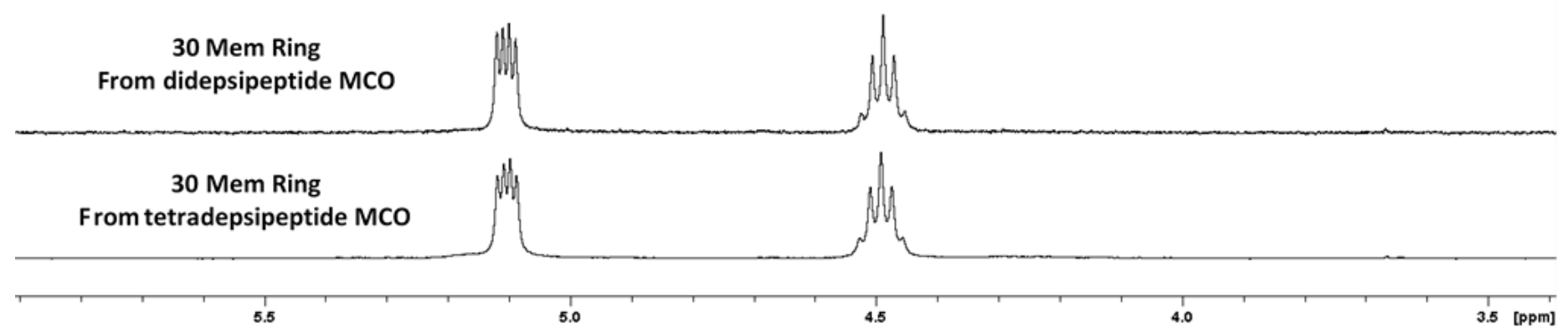

Figure S13. ${ }^{1} \mathrm{H}$ NMR of 30-membered ring (S3) samples from MCO reaction with didepsipeptide and MCO reaction with tetradepsipeptide with no residual TFA present 
Figure S14. ${ }^{1} \mathrm{H}$ NMR (600 MHz, $\mathrm{CDCl}_{3}$ ) of 11

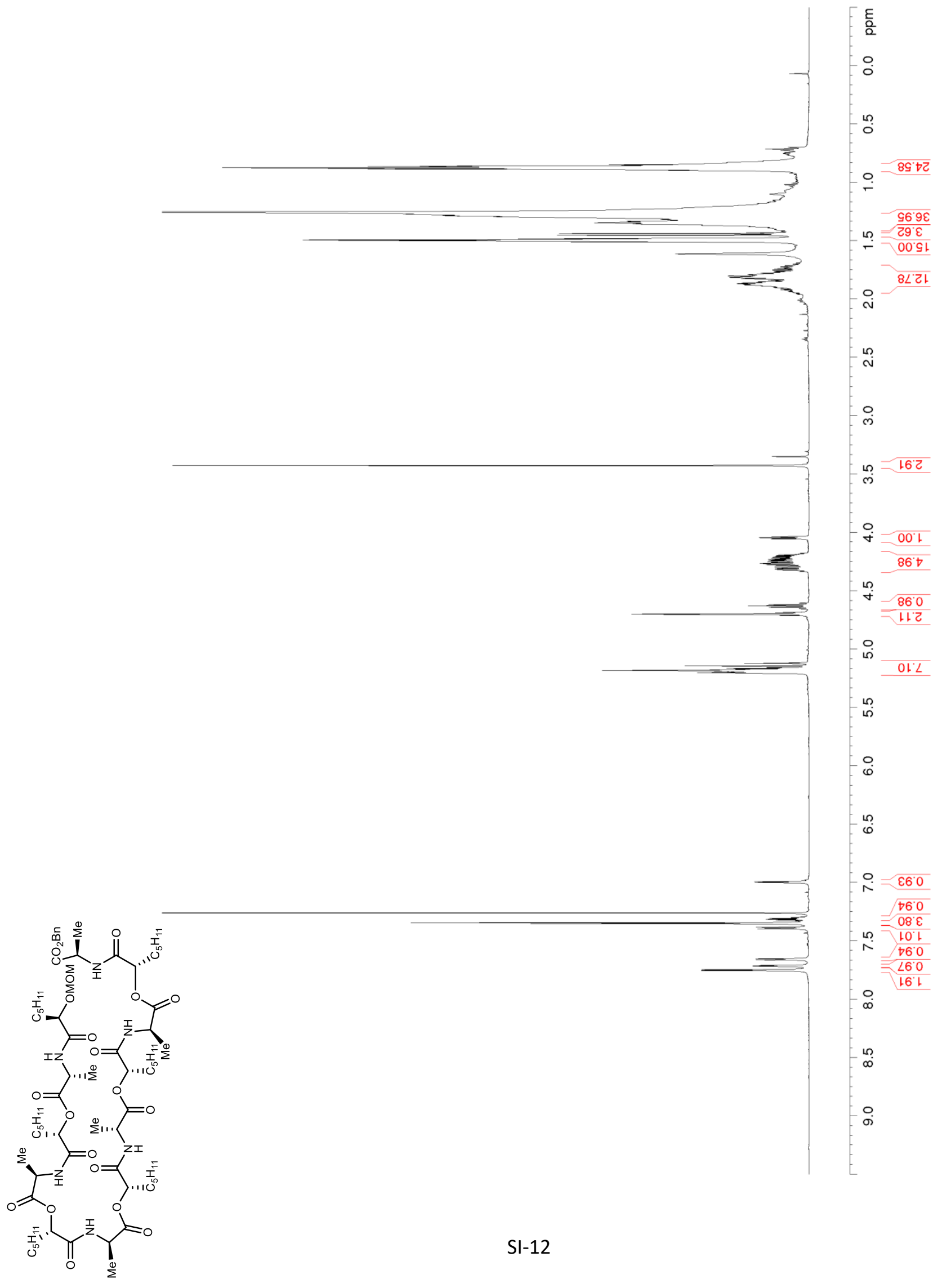


Figure S15. ${ }^{13} \mathrm{C}\left\{{ }^{1} \mathrm{H}\right\} \mathrm{NMR} / \mathrm{DEPT}\left(150 \mathrm{MHz}, \mathrm{CDCl}_{3}\right)$ of 11

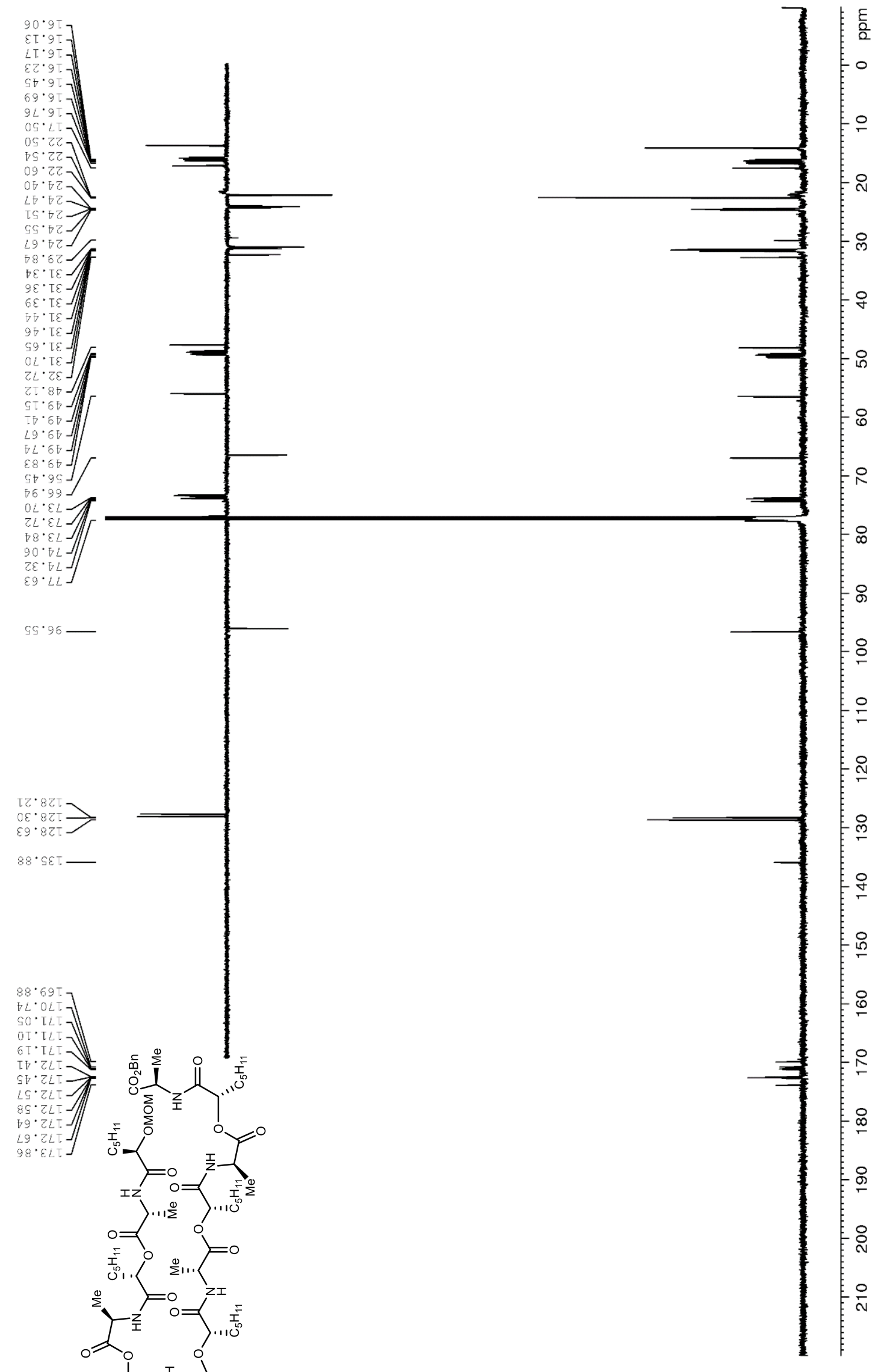


Figure S16. ${ }^{1} \mathrm{H}$ NMR ( $400 \mathrm{MHz}, \mathrm{CDCl}_{3}$ ) of 12
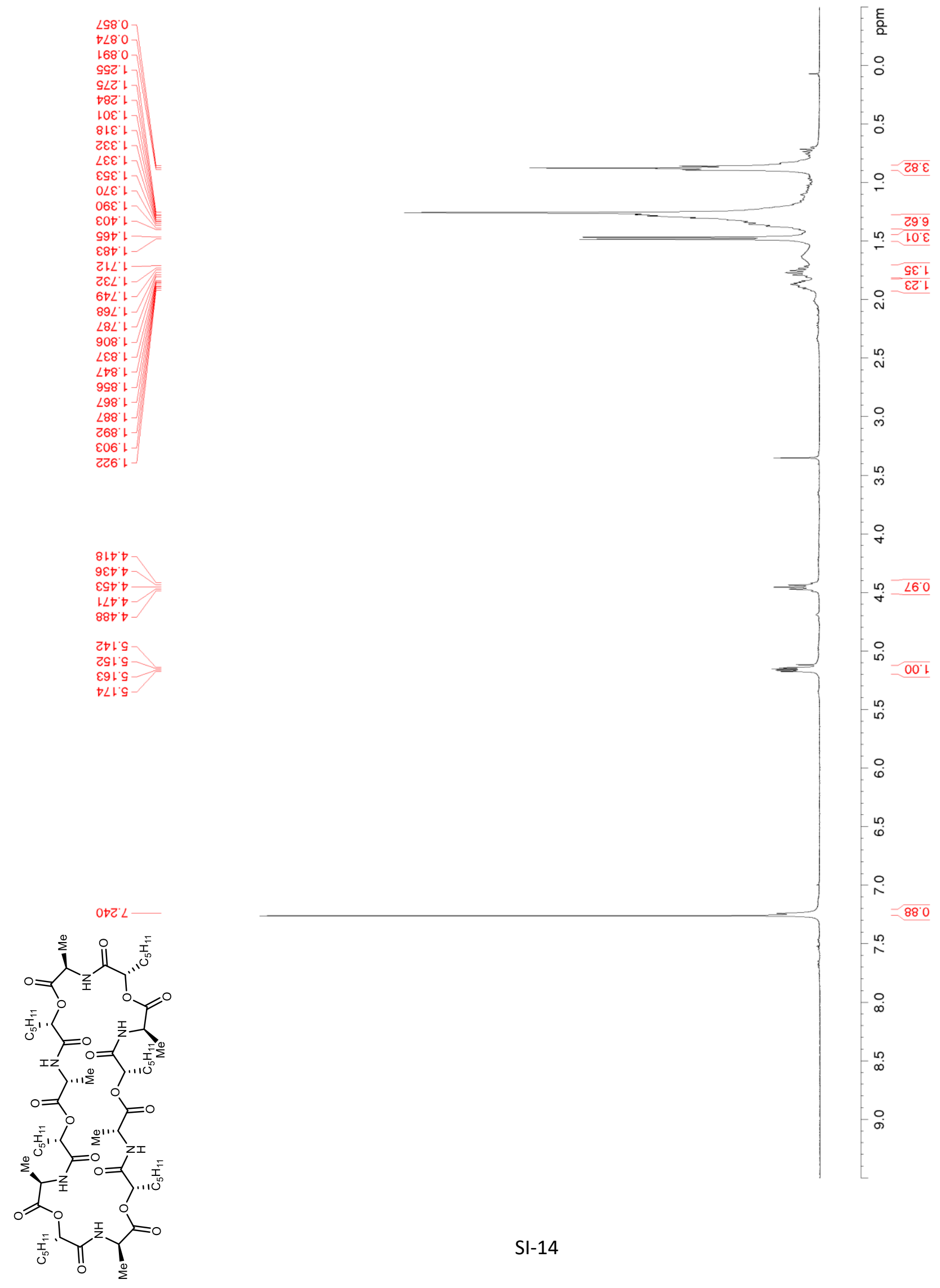
Figure S17. ${ }^{13} \mathrm{C}\left\{{ }^{1} \mathrm{H}\right\} \mathrm{NMR} / \mathrm{DEPT}\left(150 \mathrm{MHz}, \mathrm{CDCl}_{3}\right)$ of 12

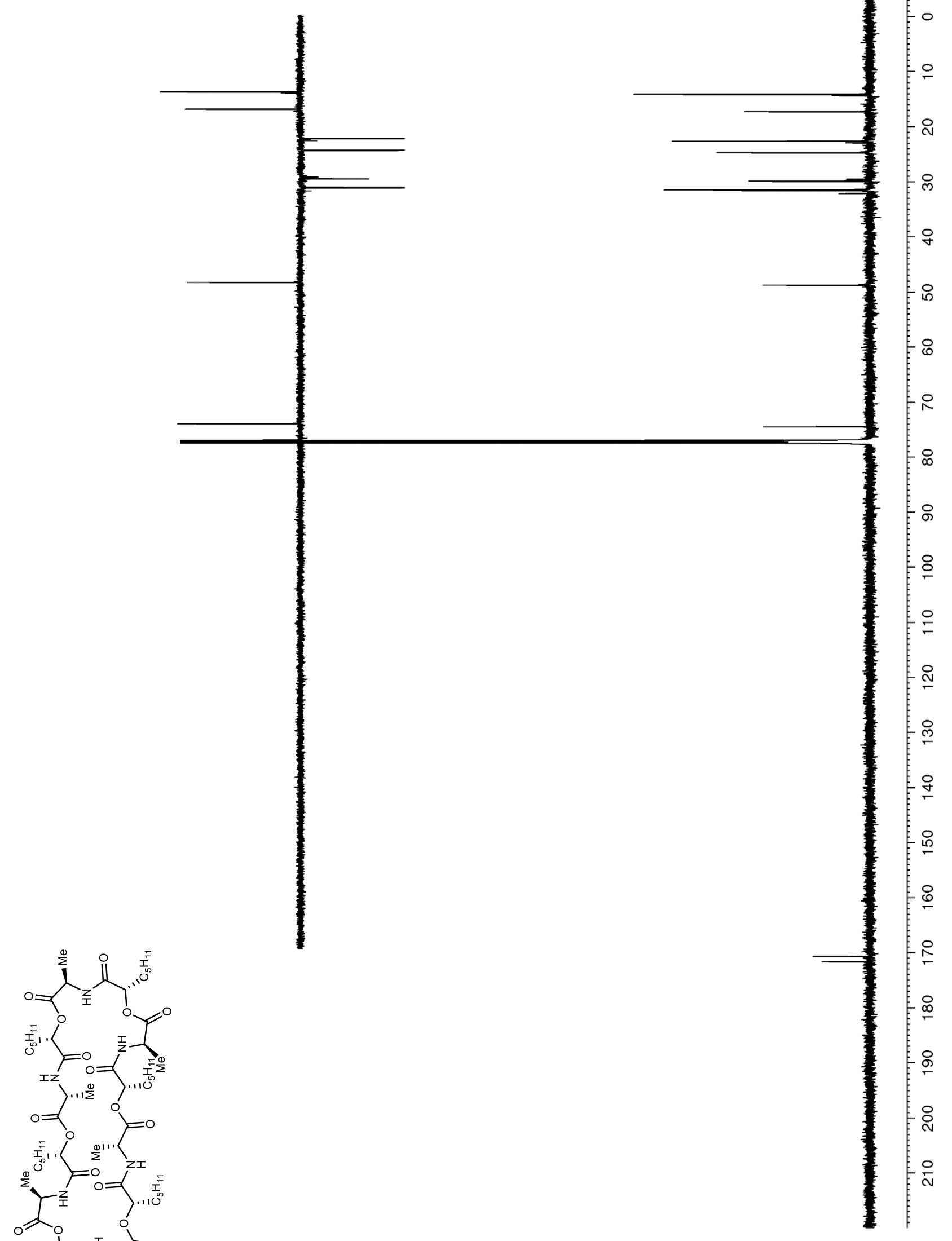


Figure S18. HRMS of 12

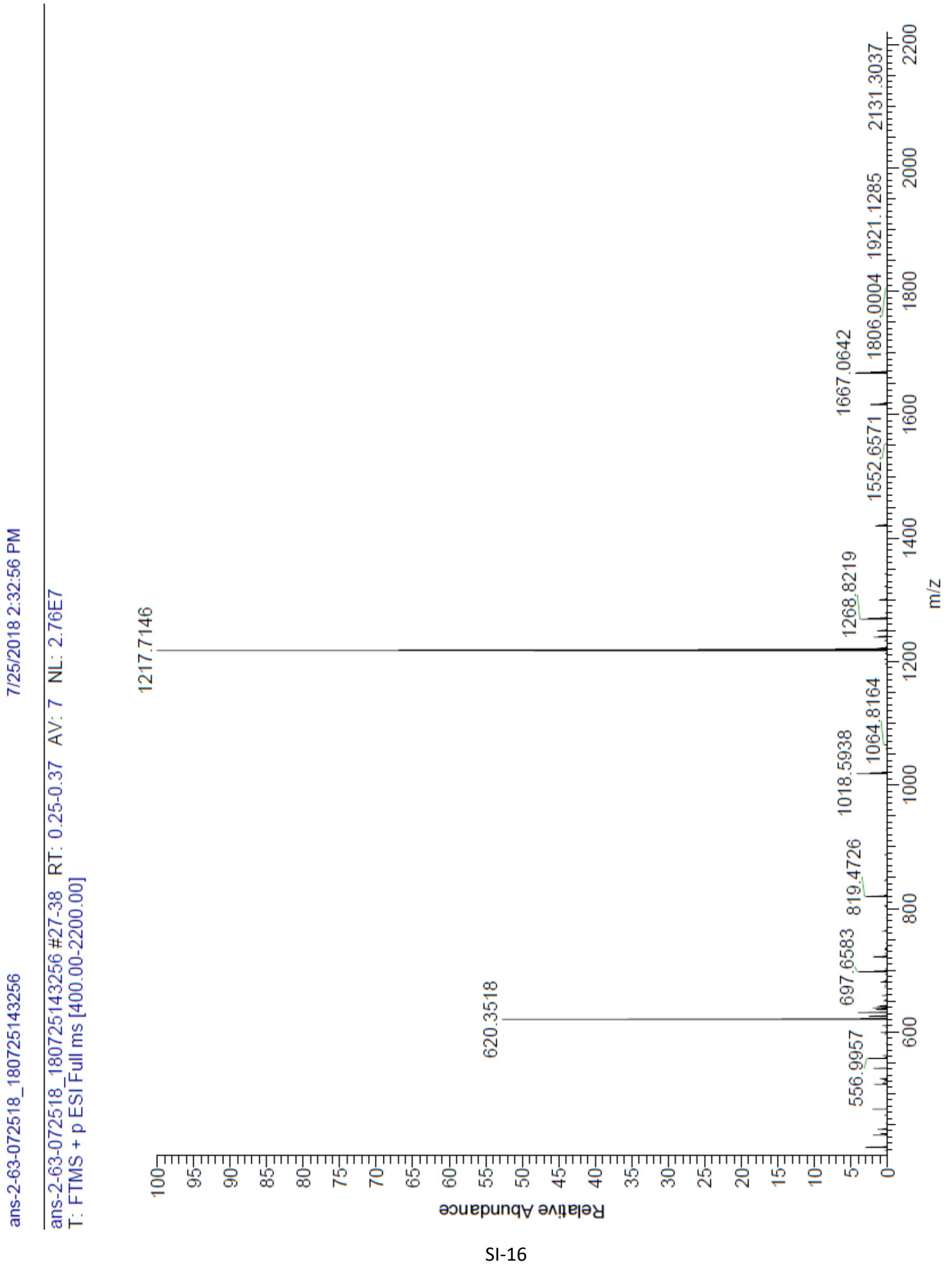


Figure S19. ${ }^{1} \mathrm{H} \mathrm{NMR}\left(600 \mathrm{MHz}, \mathrm{CDCl}_{3}\right)$ of 13

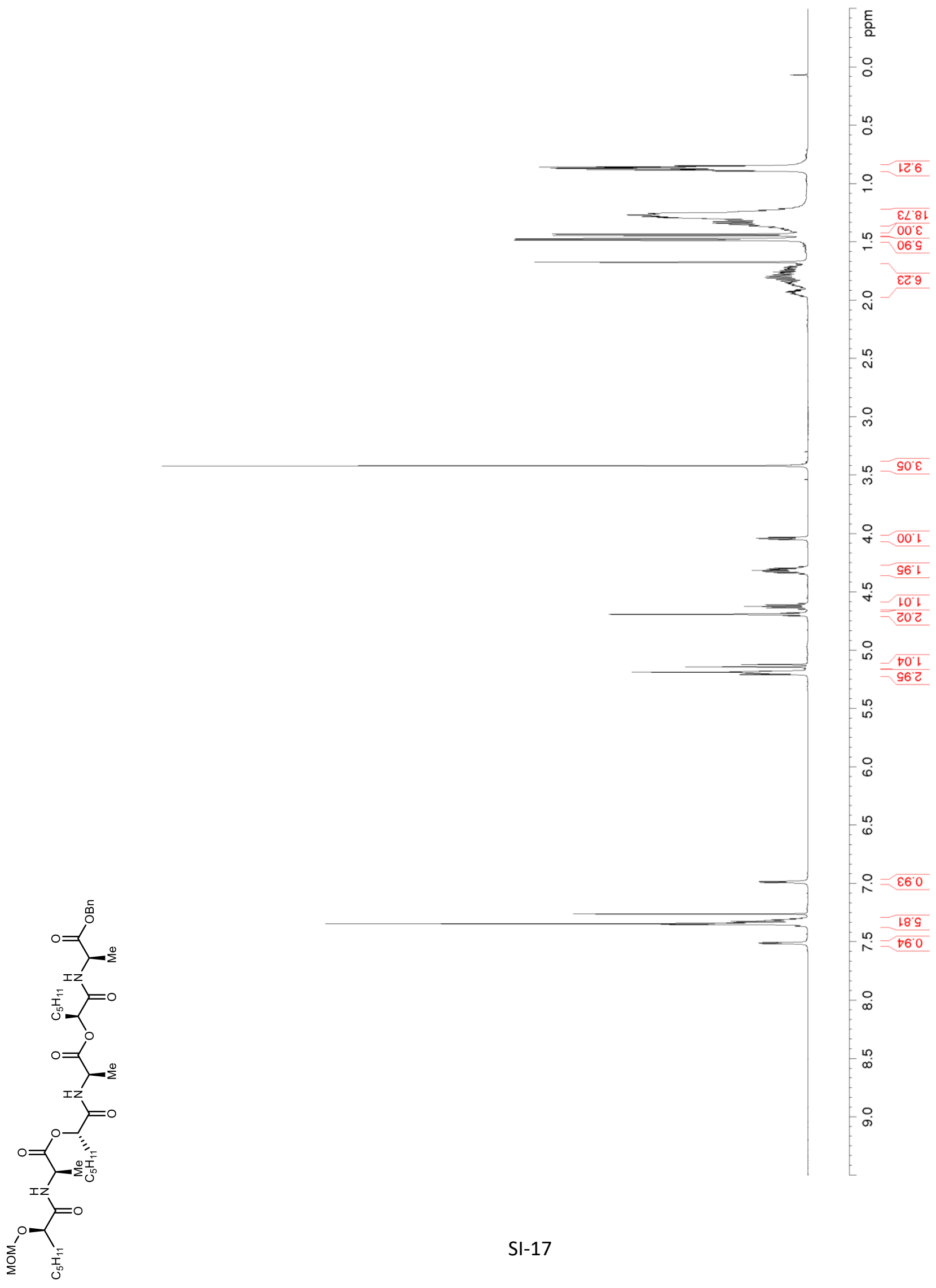


Figure S20. ${ }^{13} \mathrm{C}\left\{{ }^{1} \mathrm{H}\right\} \mathrm{NMR} / \mathrm{DEPT}\left(150 \mathrm{MHz}, \mathrm{CDCl}_{3}\right)$ of 13

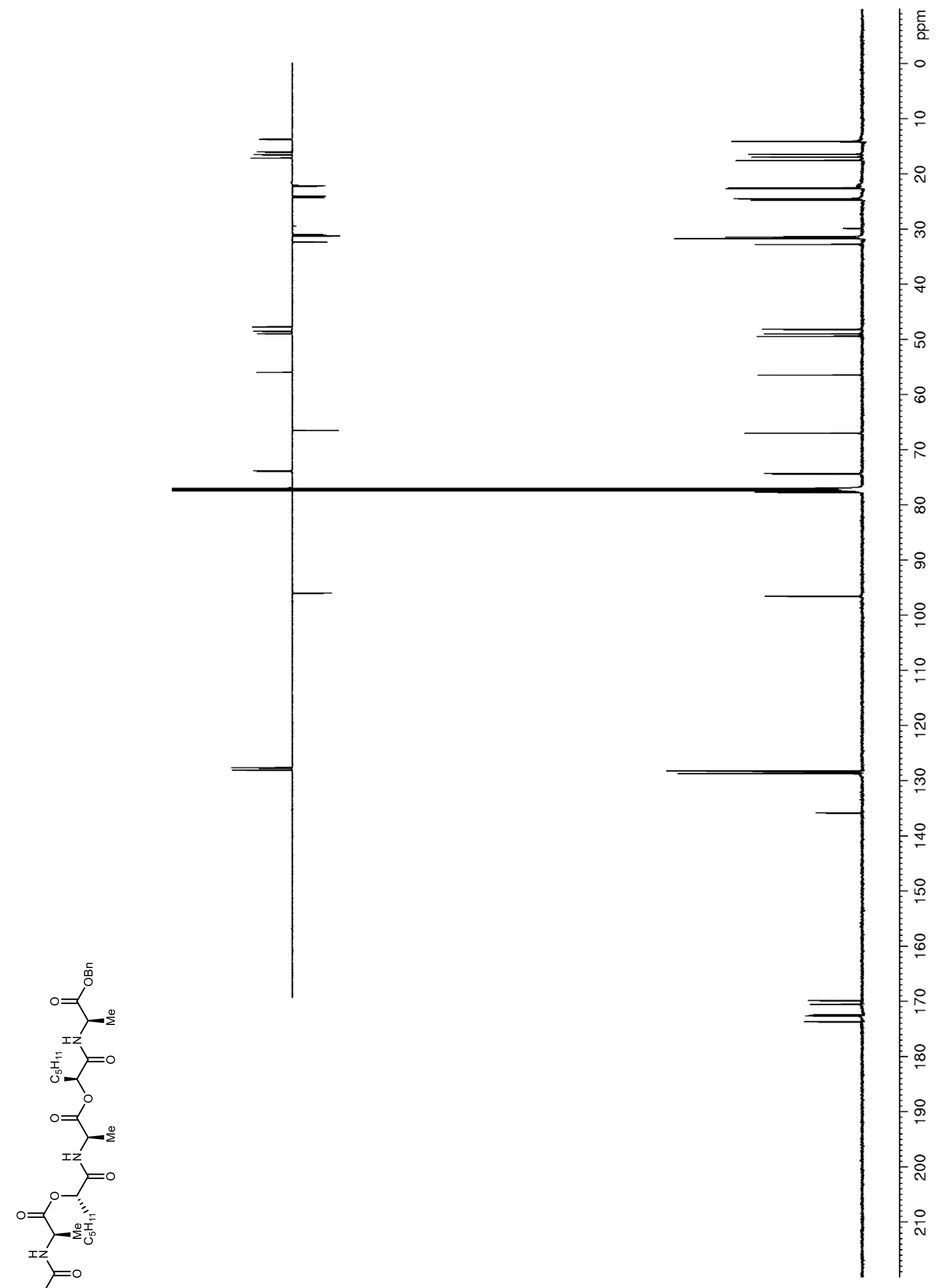


Figure S21. ${ }^{1} \mathrm{H}$ NMR ( $600 \mathrm{MHz}, \mathrm{CDCl}_{3}$ ) of 14

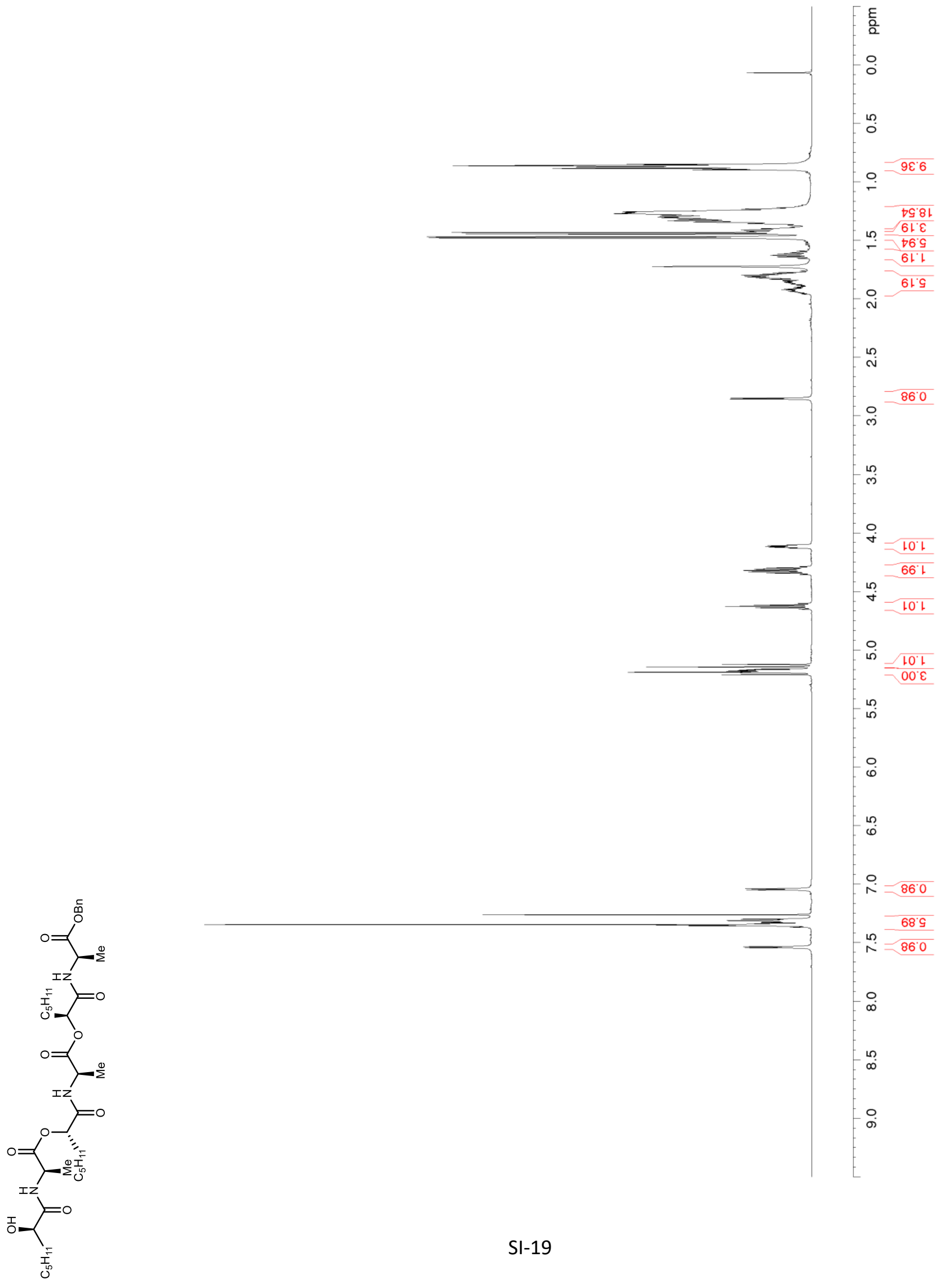


Figure S22. ${ }^{13} \mathrm{C}\left\{{ }^{1} \mathrm{H}\right\} \mathrm{NMR} / \mathrm{DEPT}\left(150 \mathrm{MHz}, \mathrm{CDCl}_{3}\right)$ of 14

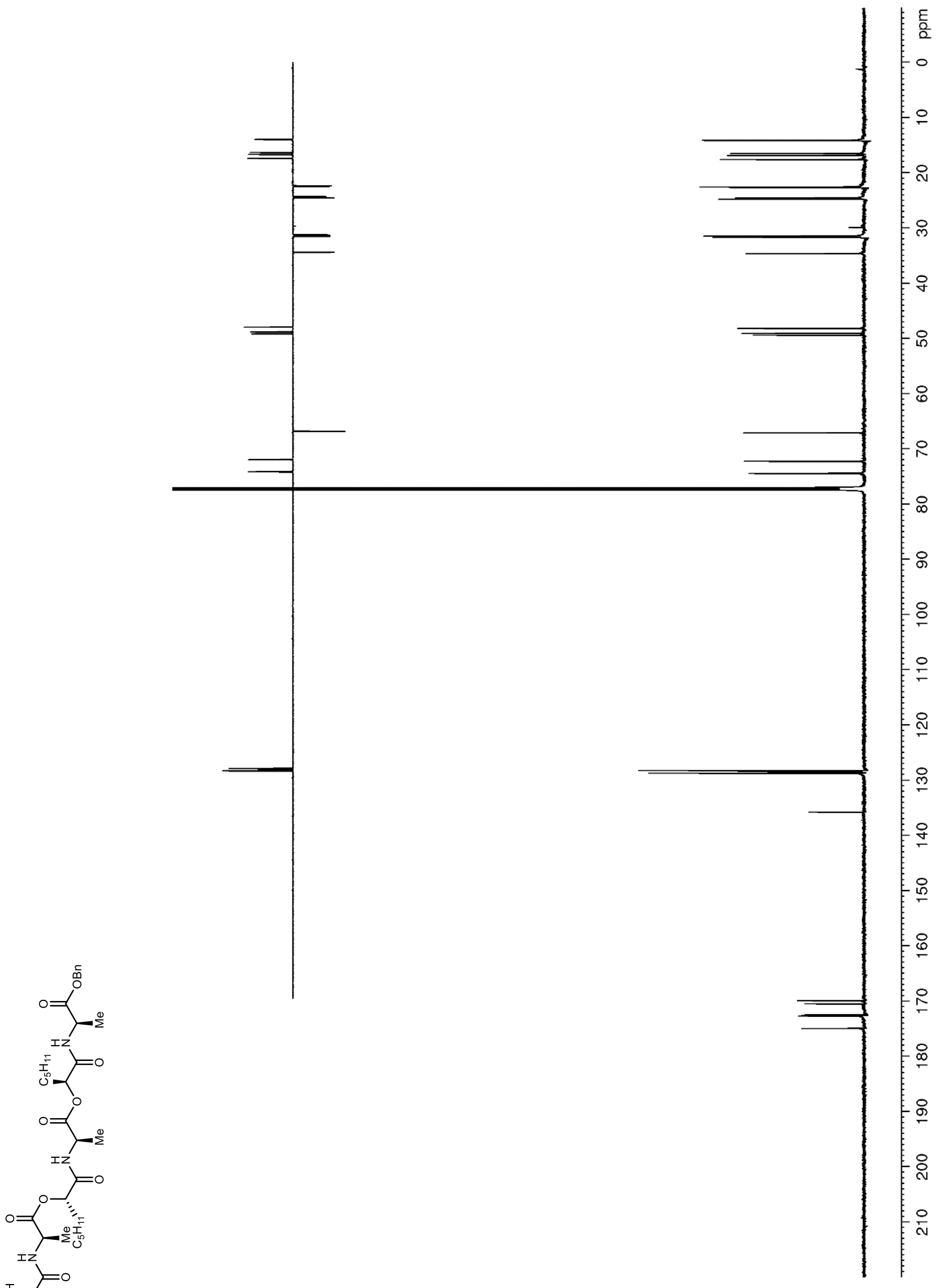


Figure S23. ${ }^{1} \mathrm{H}$ NMR (400 MHz, $\left.\left(\mathrm{CD}_{3}\right)_{2} \mathrm{SO}\right)$ of 15

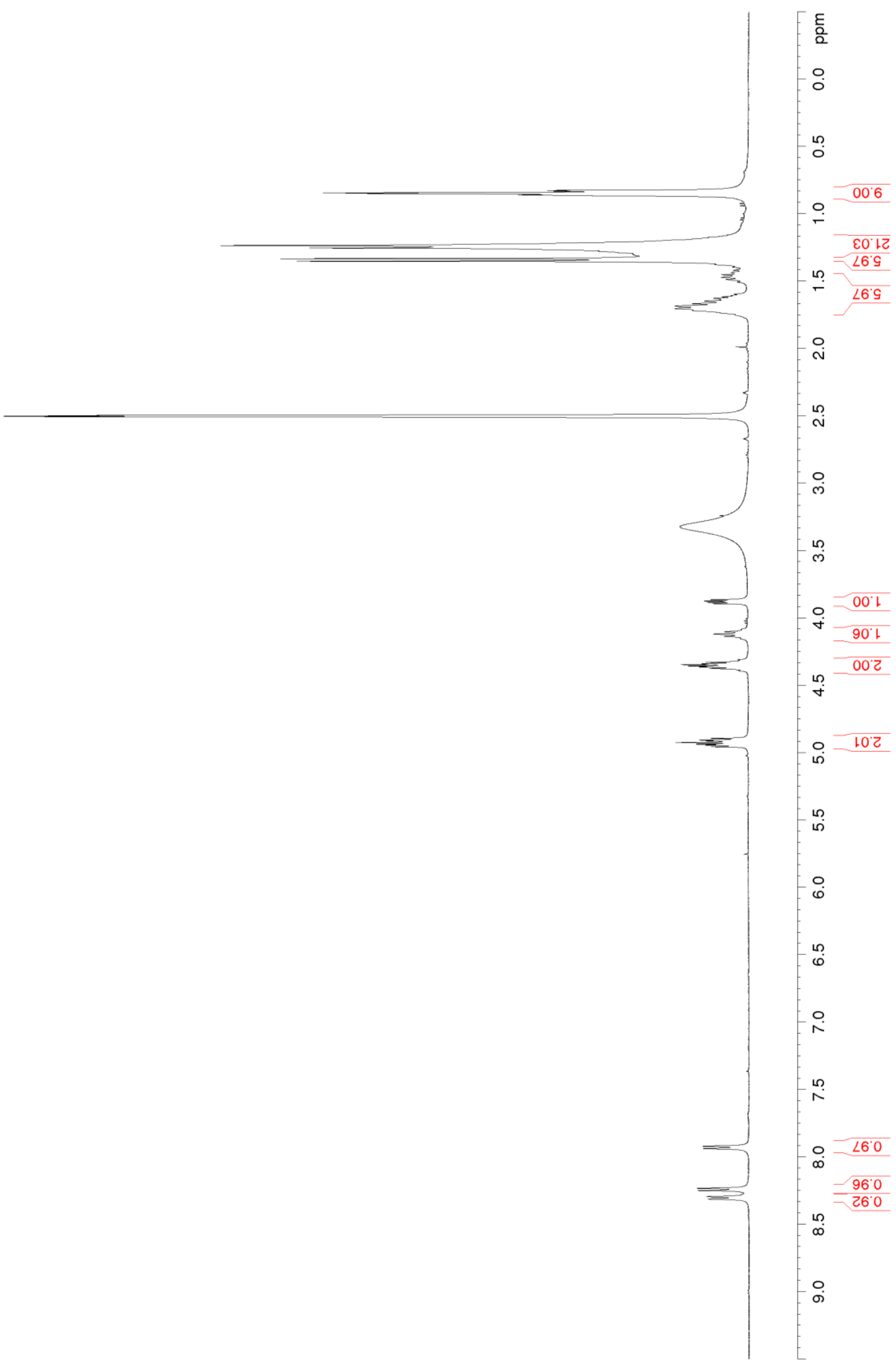


Figure S24. ${ }^{13} \mathrm{C}\left\{{ }^{1} \mathrm{H}\right\} \mathrm{NMR} / \mathrm{DEPT}\left(150 \mathrm{MHz},\left(\mathrm{CD}_{3}\right)_{2} \mathrm{SO}\right)$ of 15

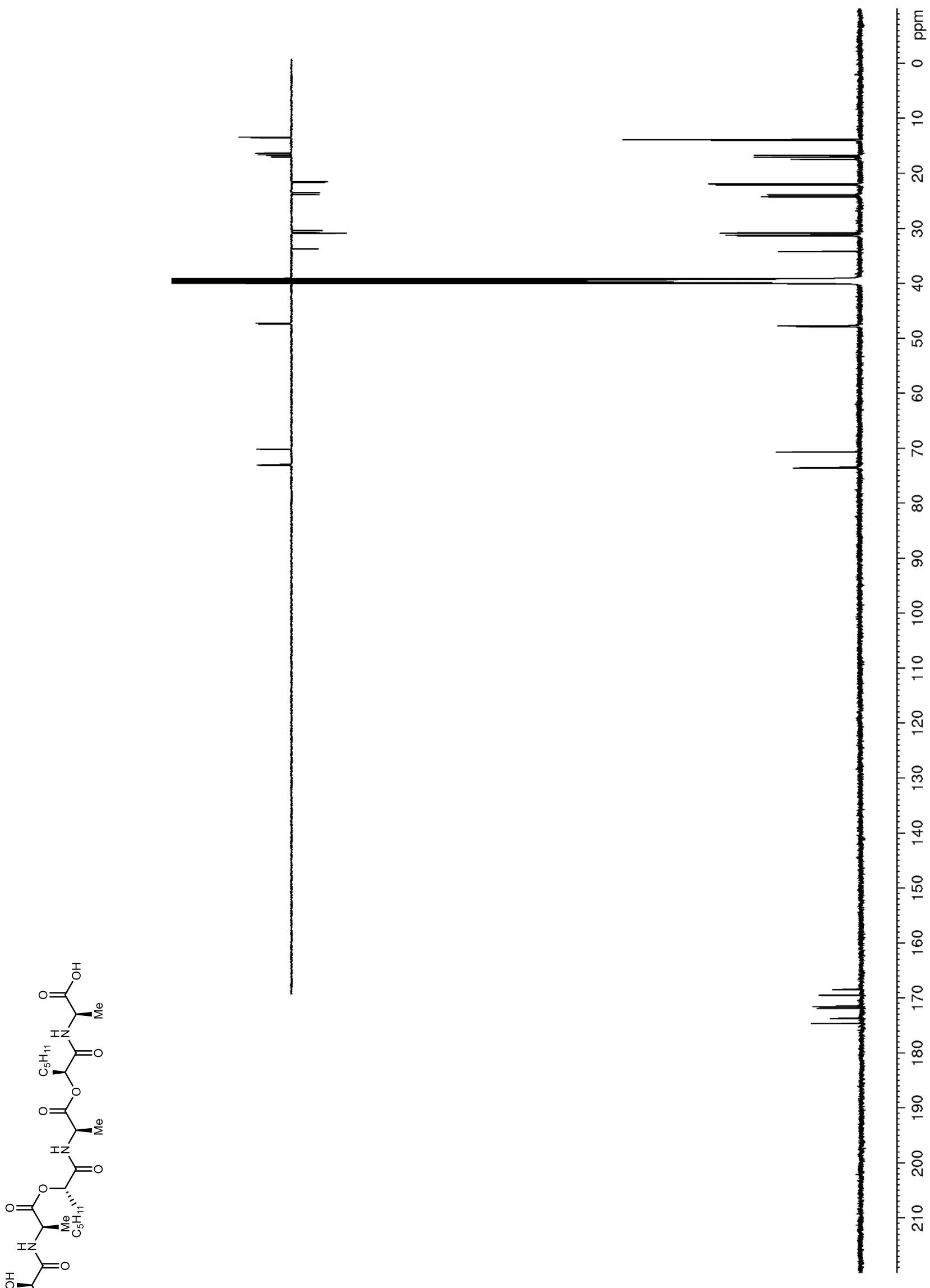


Figure S25. ${ }^{1} \mathrm{H}$ NMR (400 MHz, $\mathrm{CDCl}_{3}$ ) of 16
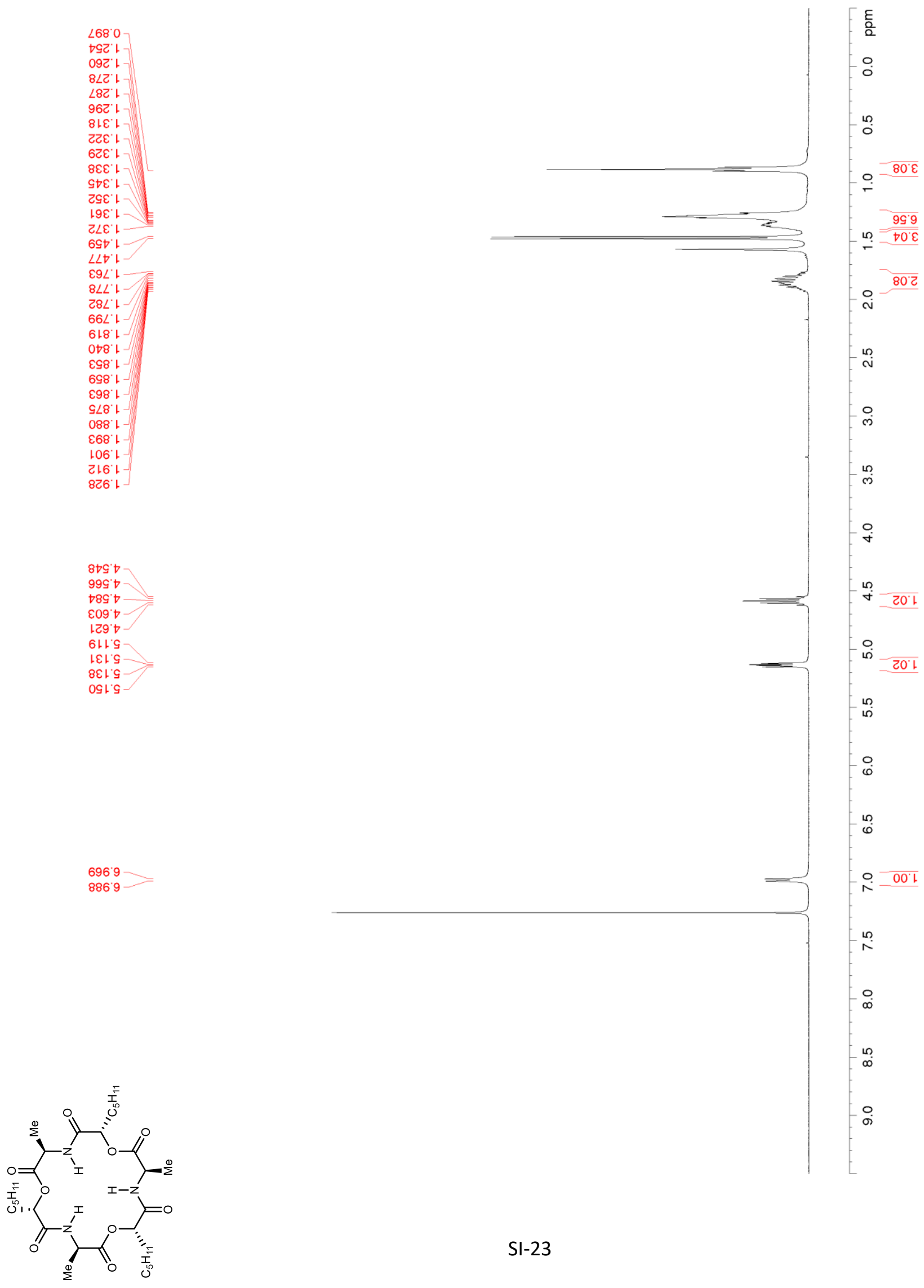
Figure S26. ${ }^{13} \mathrm{C}\left\{{ }^{1} \mathrm{H}\right\} \mathrm{NMR} / \mathrm{DEPT}\left(100 \mathrm{MHz}, \mathrm{CDCl}_{3}\right)$ of $\mathbf{1 6}$

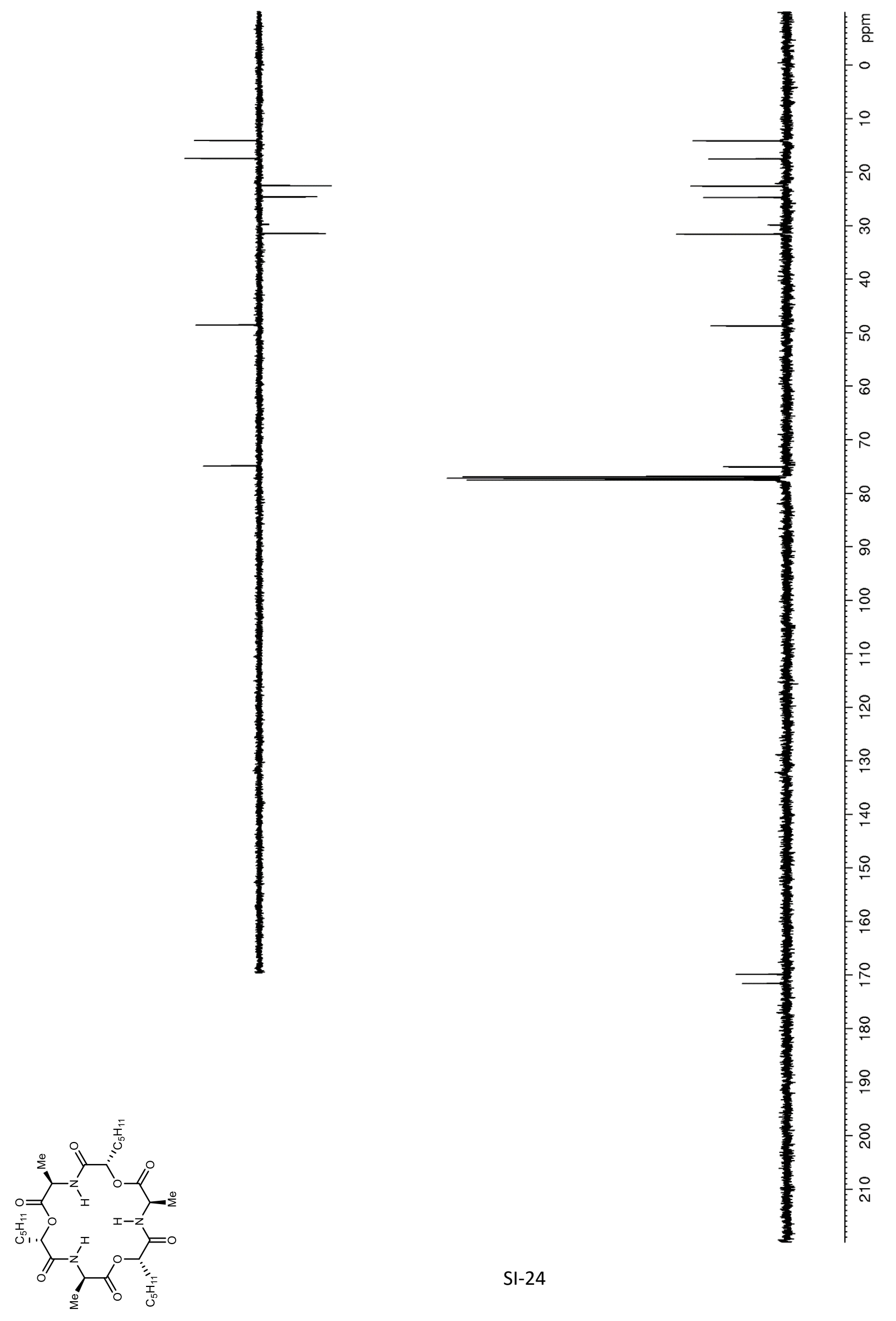


Figure S27. HRMS of 16
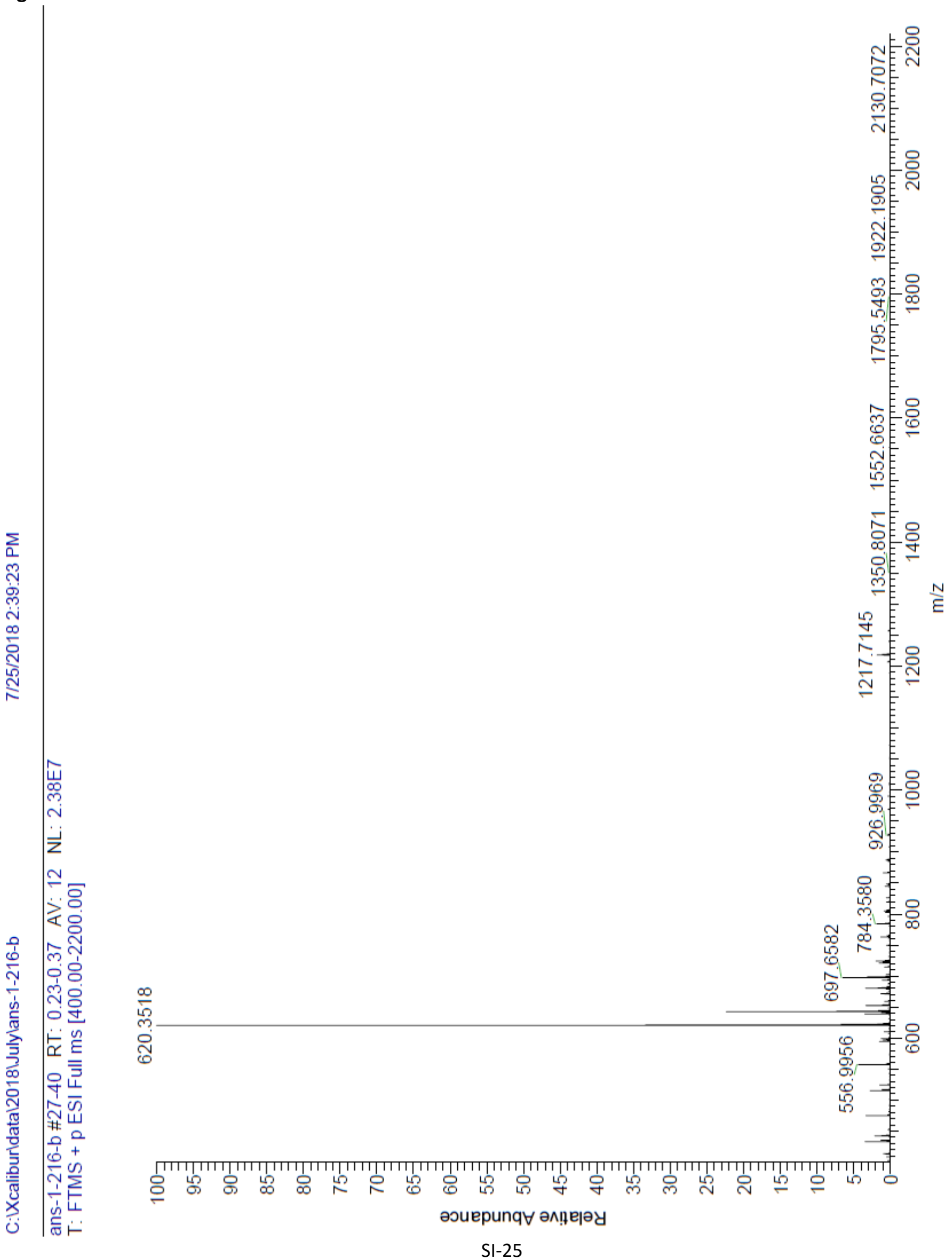
Figure S28. ${ }^{1} \mathrm{H}$ NMR ( $600 \mathrm{MHz}, \mathrm{CDCl}_{3}$ ) of $\mathbf{S 1}$

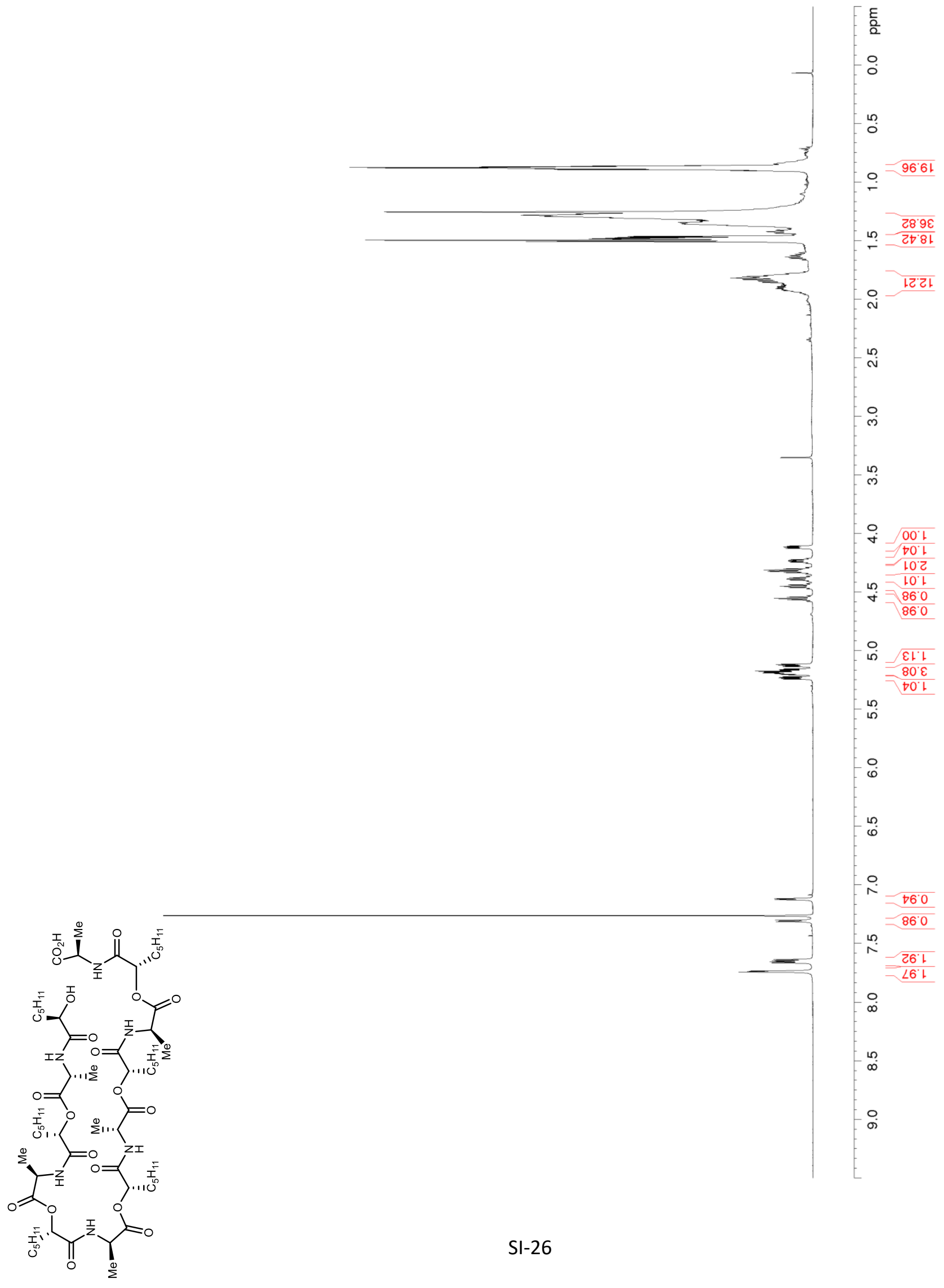


Figure S29. ${ }^{13} \mathrm{C}\left\{{ }^{1} \mathrm{H}\right\}$ NMR/DEPT (150 MHz, CDCl 3 ) of S1
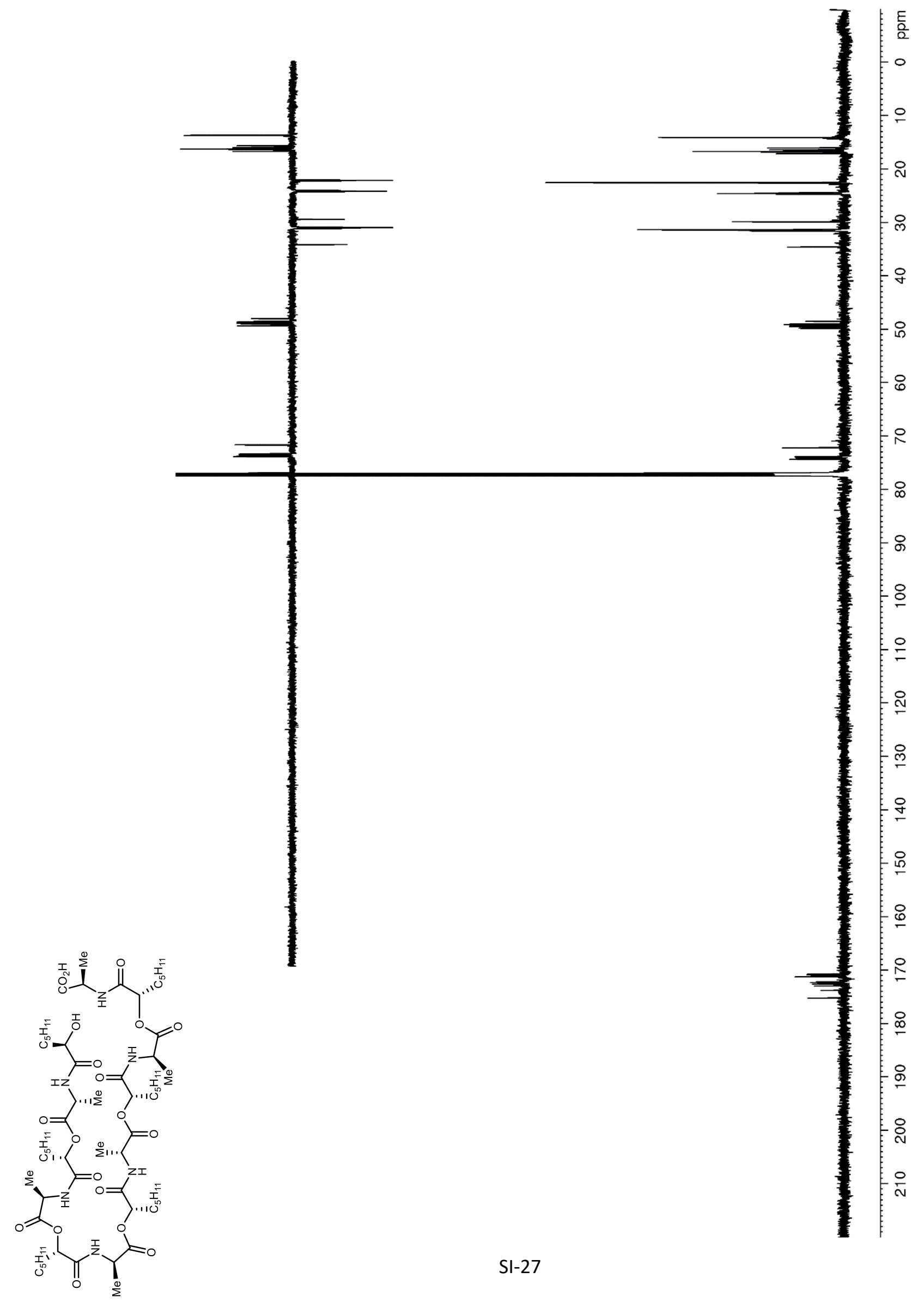
Figure $\mathbf{S 3 0 .}{ }^{1} \mathrm{H} \mathrm{NMR}\left(400 \mathrm{MHz}, \mathrm{CDCl}_{3}\right)$ of $\mathbf{S 3}$
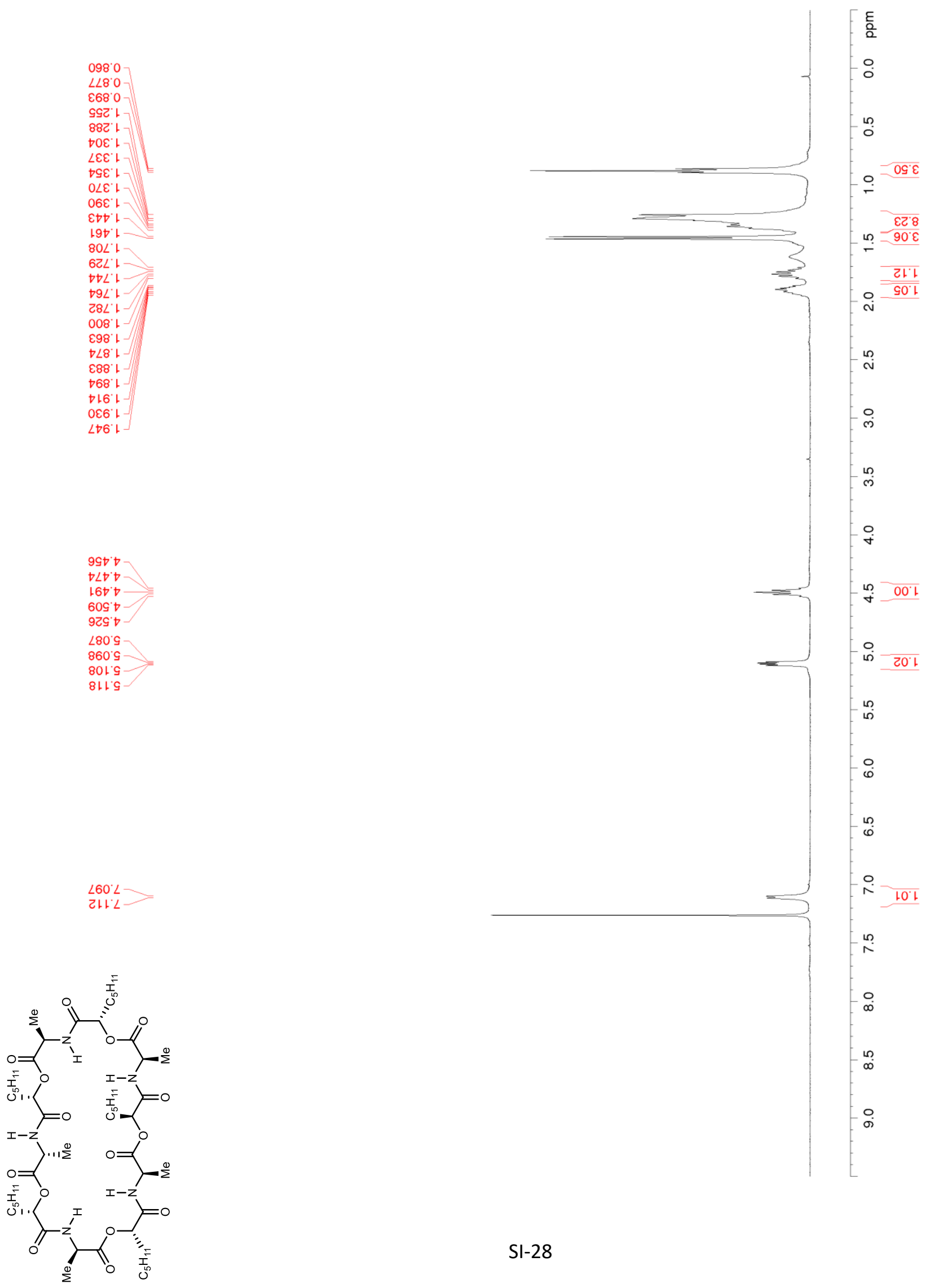
Figure S31. ${ }^{13} \mathrm{C}\left\{{ }^{1} \mathrm{H}\right\}$ NMR/DEPT $\left(100 \mathrm{MHz}, \mathrm{CDCl}_{3}\right)$ of S3

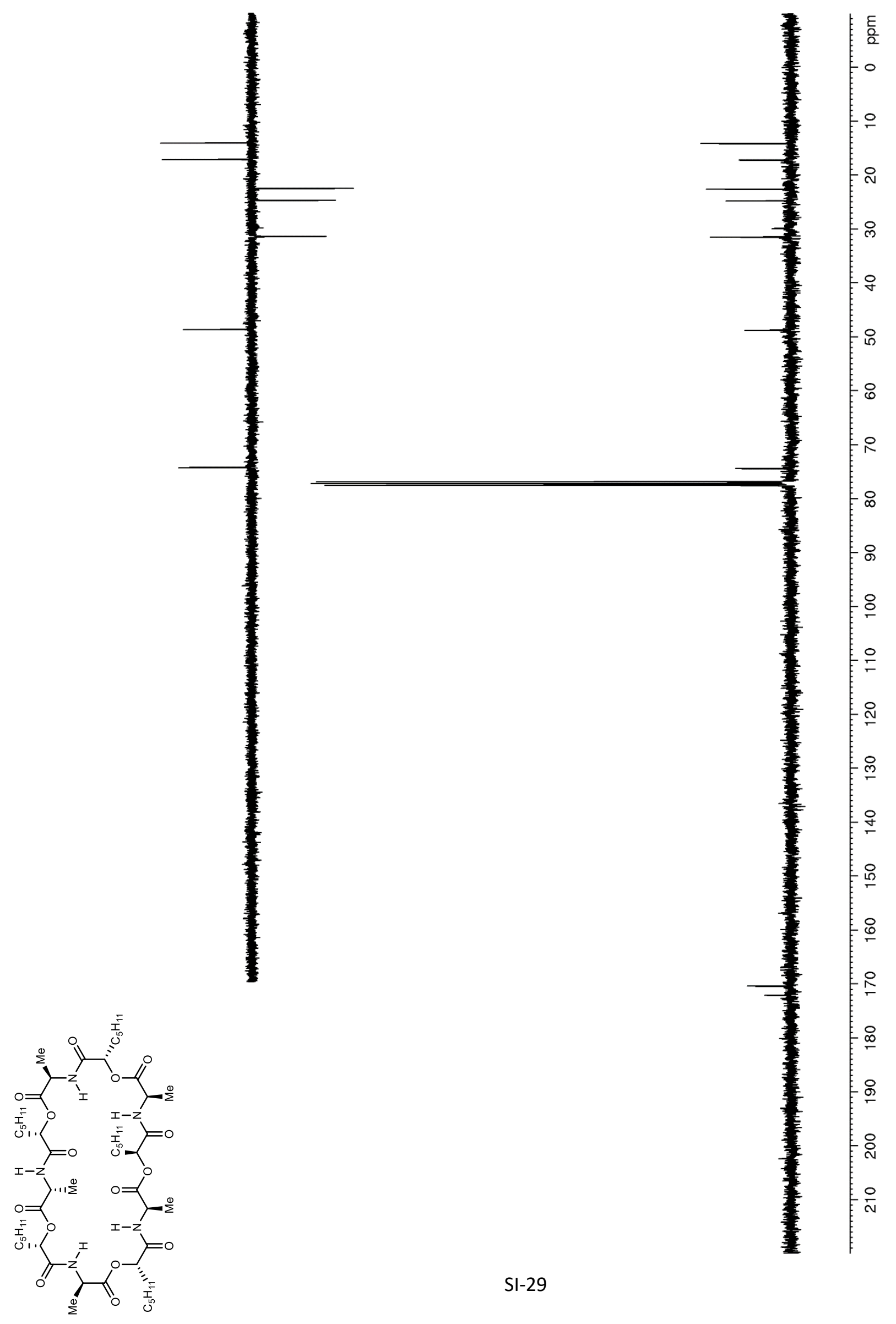


Figure S32. HRMS of S3

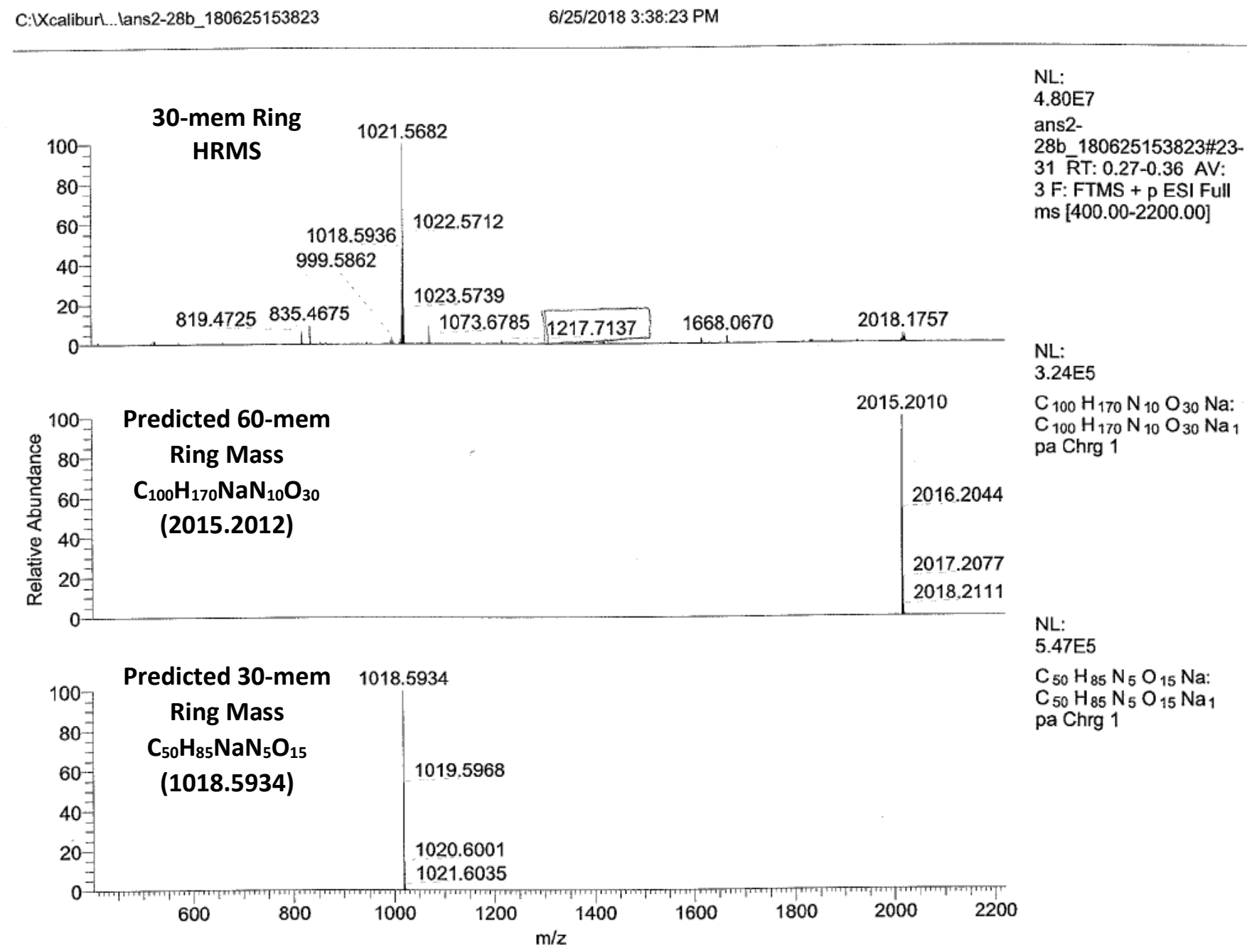

